\title{
A COGNITIVE APPROACH TO OBLIGATORY CONTROL PHENOMENA IN ENGLISH AND GERMAN
}

\author{
KLAUS-UWE PANTHER \& KLAUS-MICHAEL KÖPCKE
}

\begin{abstract}
The aim of the paper is to develop a uniform semantic-pragmatic theory of controller choice for a number of German and English subject control verbs like promise/versprechen and object control verbs like request/bitten, recommend/empfehlen, force/zwingen, etc., which prototypically require a complement clause denoting an action performed by a human agent, who is left unexpressed in the infinitive clause (PRO). We propose the concept of 'semanticpragmatic role' to account for a number of control phenomena which have hitherto been treated as exceptions. We show that controller choice and control switch heavily depend on two semanticpragmatic factors, i.e. 'degree of agentivity of $P R O$ ' and 'role identity of a matrix NP and PRO'. Furthermore, at least in English, 'iconicity', i.e. the reflection of referential identity in formal closeness, plays an important role. Our analysis is based on two experiments conducted with 35 native speakers of German and 28 native speakers of American English.
\end{abstract}

\section{INTRODUCTION}

In this paper we shall deal with sentences like (1) and (2):

(1) Bill promised Brian to buy the book.

(2) Judy persuaded Joan to buy the car.

It is well-known that sentences of this type pose an interpretive problem regarding the reference of the implicit subject of the infinitive clause: In (1) it is the referent of the matrix subject (Bill) who is expected to perform the action denoted by the infinitival complement, whereas in (2) the person referred to by the matrix object (Joan) is supposed to be the performer of the action expressed in the infinitive clause. The antecedent of the implicit subject of the embedded clause is usually called the 'controller' (cf.

Folia Linguistica $X \dot{X} V I I / 1-2$ 
Postal 1970). ${ }^{1}$ Following established usage, we shall label verbs of the promise class 'subject control verbs' and verbs of the persuade type 'object control verbs'. Furthermore, we shall call 'PRO' the empty subject position in the infinitive clause. This terminological usage is merely a matter of convenience. It does not entail that we adhere to any of the control theories which have been developed within the framework of generative grammar.

The terms 'subject control' and 'object control' misleadingly suggest that controller choice is uniquely determined by some syntactic feature of the matrix verb. However, sentences like (3) and (4), which are accepted by many speakers of English, show that this assumption is problematical:

(3) Bill promised Brian to be promoted.

(4) Judy persuaded Joan to be considered for promotion.

In (3), at least for some speakers, the preferred interpretation is that $P R O$ is coreferential with the object of the matrix clause, whereas (4), for many speakers of English, admits a reading which assigns the controller function to the subject of the main clause. This phenomenon is often called 'control switch' or 'control shift' in the literature (most recently by Larson 1991).

It is well-known that verbs which usually trigger object control by far outnumber those which typically favor subject control. A consequence of this fact is that in many control theories subject control verbs, as opposed to object control verbs, are treated as exceptions, which are consequently viewed as being marked in the lexicon, e.g. Rosenbaum (1967, 1970), Chomsky (1980), and Bresnan (1982). However, as sentences (3) and (4) demonstrate, it is easy, at least with some control verbs, to construct morpho-syntactic and semantic contexts in which speakers tend to deviate from these supposedly marked (subject control verbs) or unmarked options (object control verbs). In other words, (3) and (4) show that a purely syntactic rule (supplemented by a list

1 The notion of control was also used by Givón (1980) in the semantic sense of 'manipulation'. Köpcke \& Panther (1991) argue that the degree of manipulation denoted by the matrix verb may have an influence on control behavior (in the syntactic sense). 
of exceptional cases marked as such in the lexicon), which picks out the antecedent of the empty subject of the complement clause in a quasi-mechanical manner, is likely to be inadequate. ${ }^{2}$

In what follows, we shall briefly review some of the more important contributions to the theory of control. For ease of exposition, it is convenient to distinguish syntactically-based from semantically or pragmatically-oriented control theories.

\subsection{Syntactic approaches.}

In the 1950s Bech (1983) assumed the following basic syntactic regularity for German: Three-place verbs like bitten 'ask, request' or befehlen 'order, command' trigger object control, whereas two-place verbs like annehmen 'assume' or hoffen 'hope' trigger subject control. For English, generative syntacticians like Rosenbaum (1967, 1970) developed a Minimal Distance Principle (MDP) according to which the reference of the subject of the infinitival complement clause depends on the reference of the closest NP in the matrix clause. A version of this principle was adopted by Chomsky (1980) and recently by Larson (1991).

It is an obvious disadvantage of the MDP that it makes wrong predictions about verbs of the promise class. ${ }^{3}$ Moreover, although

2 The idea that the infinitival complement contains an implicit subject is reasonable, although other solutions of the control problem, which do not necessarily rely on this assumption, have been proposed in the literature, e.g. within the theoretical framework of Montague Grammar, cf. Bach (1979), Partee (1975), and Thomason (1976).

3

Larson (1991) is able to avoid one empirical inadequacy of Rosenbaum's MDP by postulating that control relations are determined on the level of D-Structure. Larson (1991:115) claims that the MDP can be saved if there is the additional stipulation that the controller is 'the minimal c-commanding noun phrase in the functional complex of $\mathrm{P}$ [= Predicate, K.-U.P., K.-M.K.]'. For a sentence like

John promised Mary to return home by 5:00 p.m.

Larson assumes a D-Structure in which the NP Mary is a sister of the V promised, whereas the infinitive clause is analyzed as an adjunct phrase adjoined to the V'-node which immediately dominates both V and NP. Consequently, the noun phrase Mary does not c-command the infinitival complement at this level. The only available controller c-commanding the complement clause is the subject John, which is accordingly chosen as the controller. On the other hand, in

John persuaded Mary to return home by 5:00 p.m.

the $\mathrm{V}$ persuade and the infinitive clause are sisters which are immediately 
the MDP correctly identifies the controller in cases of control switch for 'subject control' verbs (cf. (3)), it is not capable of determining the controlling NP in the case of 'object control' verbs which undergo control switch (cf. (4)). As a consequence, subsequent theories of control phenomena began to acknowledge the importance of semantic factors, e.g. Manzini (1983) and Koster (1984), although these authors still focussed on the configurational aspects of obligatory control relations.

In contrast, Bresnan (1982) argued that the controller is identified on the basis of its syntactic function. According to Bres.nan, the preferred controller is the indirect object of the matrix clause; in the absence of an indirect object, the direct object is chosen; and if there is no direct object, the subject assumes the control function. Bresnan's theory is explicitly anti-semantic, because it stipulates that only semantically non-restricted grammatical functions can play the part of (functional) controllers. Like Rosenbaum's approach her theory entails that verbs of the promise class must be marked as exceptions in the lexicon, since her control principle (wrongly) predicts that with verbs of this type the indirect object should function as the controller of PRO.

Phenomena of obligatory control have also been formalized within the framework of Montague grammar, e.g. by Partee (1975), Thomason (1976), and Bach (1979). The common denominator of these theories is that subject control verbs and object control verbs differ in their syntactic properties and that their control behavior is conditioned by these syntactic properties. Omitting technical details, the VPs of sentences.(1) and (2) have roughly the following structure in this framework:

(6) [vP [persuade+to buy the car][Joan]]

dominated by the mother node V', the NP Mary being in.the specifier (subject) position of the VP immediately dominating V'. 'The closest ccommanding node is the NP Mary, which assumes the role of controller. In Larson's theory the behavior of promise would then not have to be marked as exceptional, since it immediately follows from its syntactic behavior. 
This approach cannot adequately handle control switch phenomena, unless the ad hoc assumption is made that promise and persuade each have two lexical entries differing in syntactic subcategorization, ${ }^{4} \mathrm{cf}$ also the lexicalist approach put forward by Bartsch (1978).

\subsection{Semantic and pragmatic approaches}

Jackendoff (1972), though still arguing within the framework of generative grammar, stressed the importance of case roles or theta-roles in the formulation of an adequate theory of control phenomena. For example, with a verb like get, the thematic role 'theme' is always the controller, irrespective of its syntactic position, whereas promise selects the 'source' as the controller. However, as was pointed out by Foley \& Van Valin (1984:306),

“... Jackendoff does not attempt to derive the source control of promise or the theme control of get from the semantics of these verbs in any principled way, and consequently the specification of the controller in the lexical entry is ultimately arbitrary and non-explanatory."

A considerable step forward was taken by R̊̊žička (1983a,b). According to him, control verbs should be divided into two distinct classes: The first class, which includes verbs like promise, requires thematic identity or, at least, similarity between the controller and PRO; whereas the second class, which is exemplified by persuade, is subject to a constraint of thematic distinctness between the controller and controlled element. One important advantage of Ri̊ziččka's theory is its ability to account for a number of control switch phenomena, which were left unexplained by previous theories. A drawback of Růžička's account is that, although it mentions some pragmatic factors, which may have an influence on the assignment of control relations, it does not incorporate these observations into a unified theory.

Chierchia (1983) put forward the hypothesis that unmarked controller choice is determined by a hierarchy of thematic roles. Preferably, the controller is supposed to be the Theme; if there

4 For a more detailed analysis and a critical assessment of the Montague approach to control phenomena, see Panther (in prep.). 
is no Theme, the Source will be selected; and if there is no Source, the Goal will function as the controller. This approach is hardly convincing, because it categorizes the relatively small class of promise-type verbs as being (relatively) unmarked, selecting Source as the controller, whereas the large class of object control verbs like require, order, ask, and tell, which choose the Goal instead of the Source as their respective controllers, are treated as marked cases.

Foley \& Van Valin (1984) proposed a theory of control phenomena which is grounded in the supposedly. universal semantic functions 'actor' and 'undergoer'. The authors divided control verbs into 'undergoer control' verbs (causative verbs and directive speech act verbs) and 'actor control' verbs (e.g. promise, vow). Their theory predicts that verbs which can be used in a directive and a non-directive meaning should allow both control possibilities: 'undergoer' control, if the interpretation is directive, and 'actor' control on a non-directive reading, e.g. as in (7) and (8):

(7) John asked Bill to sing something. (directive verb, therefore 'undergoer' control)

(8) John asked Bill what to sing. (non-directive, therefore 'actor' control)

Foley \& Van Valin claimed that their theory avoids the shortcomings of Rosenbaum's, Chomsky's and Jackendoff's proposals. However, it seems to us that their approach has fatal flaws: Consider e.g. the German sentences (9) and (10):

(9) John bat Bill, das Zimmer zu verlassen.

'John asked Bill to leave the room'

(10) John bat Bill, das Zimmer verlassen zu dürfen.

'John asked Bill to be allowed to leave the room'

In terms of Foley \& Van Valin's theory (9) is a case of 'undergoer' control, and (10), with John as the controller, exemplifies their 'actor' control. However, this control switch cannot be explained by postulating a directive meaning, as in (9), in contrast to an allegedly non-directive meaning, as in (10). Foley \& Van Valin's theory entails that the verb bitten has two lexical entries. In our view, there is no plausible semantic reason for this assumption. 
More promising theories of control phenomena have been developed by Comrie (1984, 1985), Farkas (1988), Ladusaw \& Dowty (1988), Wegener (1989), and Sag \& Pollard (1991). Comrie noted the role of the notion of 'degree of agentivity' in the assignment of the controller, and, for the first time, pointed out some possible differences in control behavior among languages like English, German, and Russian. Farkas (1988) introduced the closely related notion of 'responsibility'. She claimed that, in the unmarked case, the controller is the Agent who is responsible for the situation expressed in the infinitive clause. The advantage of this semantic solution is that the subject control verb promise no longer needs to be marked as an exception. However, Farkas had to postulate a principle of 'marked controller choice' to account for control switch phenomena.

Ladusaw \& Dowty (1988:69) argued that 'principles of rational actions and verb entailments' underlie the control behavior of verbs like promise, persuade, and ask, which have been 'grammaticized', i.e. have become 'a learned part of the grammar'.

Recently, Sag \& Pollard (1991) have proposed a semantic principle of obligatory control, which is supplemented by a syntactic principle based on their version of binding theory. A weak point in their approach is that their semantic control principle rests on a taxonomy comprising three distinct classes of control verbs: (i) the ORDER/PERMIT type (e.g. advise, allow, forbid, order, etc.), (ii) the PROMISE type (e.g. agree, choose, decide, demand, promise, try, etc.), and (iii) the WANT/EXPECT type (e.g. ache, desire, hate, want, etc.). Informally, Sag \& Pollard's semantic control principle says that with verbs of class (i) the semantic role called the INFLUENCED controls the covert subject of the infinitive clause. For verbs of class (ii), the COMMITTOR, and for verbs of class (iii), the EXPERIENCER functions as the controller. In principle, we share Sag \& Pollard's view that control phenomena have a semantic (or better, pragmatic) basis, i.e. that, among other things, control assignments depend upon the meaning of matrix verbs.

However, to our mind, the classification into three distinct types of control verbs misses a significant generalization. It is the aim of our paper to show that it is possible to treat (obligatory) control as a uniform semantic-pragmatic phenomenon. More. 
specifically, Sag \& Pollard's semantic classification seems to us to be ultimately motivated not by semantic but by syntactic considerations. E.g., it is quite obvious that the class of control verbs listed under (ii) is semantically heterogenuous. Some of the verbs are illocutionary verbs like promise, vow, pledge, etc., others denote extralinguistic activities like try, attempt, endeavour, etc. or mental states like intend. But even the subset of illocutionary verbs is not semantically uniform. There is at least one verb, viz: demand, which, from a semantic point of view, does not belong to class (ii) at all, but rather to class (i). The only difference between demand and the other members of class (i) is that with demand the INFLUENCED is not lexicalized. But since members of class (i) trigger object control, demand, which in modern English is a subject control verb, does not fit into class (i) syntactically. ${ }^{5}$ Thus, we suspect that, although the authors claim that they provide a semantic taxonomy of control verbs, in fact, their classification is at least partially founded upon (unadmitted) syntactic criteria. From a semantic point of view, their control principle must be regarded as partially arbitrary and non-explanatory.

On the syntactic level, Sag \& Pollard (1991:79) regard PRO as an anaphor, which is subject to Principle $A$ of their version of binding theory: "A locally o-commanded anaphor must be locally o-bound.." This principle seems to account for many English control phenomena, but it is not universally valid, as the authors seem to imply. Consider, for example, sentences (11)a. $-\mathbf{c}^{6}$

(11) a. Hans riet [PRO früh aufzubrechen].

Hans advised [PRO early to leave]

b. *Hans advised to leave early.

c. Hans advised PRO leaving early.

5 The verb demand could be used as an object control verb as late as in the 18th century. Originally, it was possible to use demand with a lexicalized matrix object NP. As soon as, for whatever reason, this NP was (obligatorily) dropped demand changed into a subject control verb.

6 Other German control verbs exhibiting the same control properties as raten include befehlen 'order', bitten 'ask', drängen 'urge', empfehlen 'recommend', etc. For all these verbs, the controller may remain implicit, whereas in the case of anordnen 'order' the controlling element must remain implicit, e.g.

Der Präsident ordnete an, die Universität zu schließen.

'The president ordered the university to be closed' 
Sag \& Pollard's binding principle correctly predicts that (11)b. should be ungrammatical. Their (semantically-based) control theory determines the INFLUENCED as the controller. Consequently the matrix subject Hans (the INFLUENCE) cannot be the antecedent of PRO. On the other hand, Sag \& Pollard's binding principle $A$ requires that the referential matrix argument Hans, which locally o-commands the anaphor PRO, be (incorrectly) coindexed with the latter. Thus one might be tempted to account for the ungrammaticality of (11)b. as resulting from the conflicting stipulations of control theory and binding theory. However, if this is the correct explanation, then examples like (11)a., which is fairly representative of a large class of cases in German (cf. Rohdenburg (1991)), and (11)c. should also be ungrammatical. These cases obviously involve 'implicit' control: the controlling element can usually be retrieved from the discourse context. In any case, data like (11)a. and (11)c., where the controller is not lexicalized but contextually present, cast doubt upon the hypothesis that the referential interpretation of $P R O$ can be explained in terms of binding theory.

To summarize, an adequate theory of obligatory control faces three important problems:

(i) It must give a cognitively plausible and, if possible, uniform account of how speakers select the appropriate controller.

(ii) It must explain the apparently exceptional behavior of the promise type verbs.

(iii) It must provide a theoretically satisfactory and an intuitively appealing account of control switch phenomena.

In our view, it is not sufficient to postulate configurationallymotivated conditions for obligatory control and to do away with the semantic and pragmatic aspects of controller choice and control switch as residual problems, cf. Manzini (1983), Larson (1991). It is the central aim of this paper to demonstrate that the interpretation of control structures is heavily guided by semantic, pragmatic, and cognitive factors. More specifically, we will propose an account of control phenomena which is centered around the notions of 'prototype' and 'semantic-pragmatic role' (see section 2).

We shall restrict our attention to a certain class of (wellknown) subject and object control verbs. Our analysis is based 
on experimental data, which were obtained from native speakers. We conducted experiments because, in our view, one major deficiency of previous control theories is that the acceptability of the sentences discussed in the literature almost exclusively depends on the linguistic intuitions of the investigator or, in the case of foreign languages, on data which have been adopted from other linguists. The acceptability tests which we carried out with both German and (American) English native speakers reveal some common properties, but also a number of interesting differences between these two languages with respect to their control behavior. To our knowledge, these differences have not been recognized so far. Furthermore, it turned out that the linguistic intuitions of native speakers frequently differed quite radically from those taken for granted in the literature on the subject.

\section{HYPOTHESES}

In our experiments we analyzed instances of five semantic verb classes given below (Table 1). ${ }^{7}$

Table 1: Verb classes tested in the experiments

\begin{tabular}{|l|l|l|}
\hline Verb class & English control verbs & German control verbs \\
\hline COMMISSIVES & $\begin{array}{l}\text { promise } \\
\text { give one's word }\end{array}$ & $\begin{array}{l}\text { versprechen } \\
\text { zusagen }\end{array}$ \\
\hline CONSULTATIVES & recommend & $\begin{array}{l}\text { empfehlen } \\
\text { raten }\end{array}$ \\
\hline DIRECTIVES & $\begin{array}{l}\text { request } \\
\text { implore }\end{array}$ & $\begin{array}{l}\text { bitten } \\
\text { beschwören }\end{array}$ \\
\hline PERLOCUTIVES & $\begin{array}{l}\text { convince } \\
\text { persuade }\end{array}$ & $\begin{array}{l}\text { überzeugen } \\
\text { überreden }\end{array}$ \\
\hline IMPLICATIVES & $\begin{array}{l}\text { induce } \\
\text { force }\end{array}$ & $\begin{array}{l}\text { veranlassen } \\
\text { zwingen }\end{array}$ \\
\hline
\end{tabular}

7 Note that in using the terms commissives, consultatives, directives, and perlocutives we do not refer to speech acts, but to verbs which denote illocutionary or perlocutionary acts. Furthermore, the English verbs and their German counterparts are not necessarily synonymous, although they are similar in meaning. 
We assume that these matrix verbs evoke an action schema, which sets the stage for the interpretation of the complement clause; i.e. the verbs in Table 1 have in common that they 'ideally' or 'prototypically' require a complement clause with an action predicate in the active voice, $c f$. sentences (1) and (2) above. Even if the complement clause contains a non-actional predicate, it will always be interpreted as being part of an action schema.

There are at least five arguments which support a 'prototypical' approach to control phenomena:

(i) It is obvious that, with regard to the matrix verbs investigated, infinitivals expressing an action which is syntacticized in the active voice are much more frequent than any other infinitival complement types.

(ii) Our experiments reveal that native speakers hardly ever reject sentences with an action complement, whereas the rejection rate for other infinitival complement structures, e.g. passives, is significantly higher.

(iii) The degree of agreement among the experimental subjects regarding controller choice is much higher in the case of action complements than for other complement types.

(iv) Professional linguists show a high degree of agreement concerning the acceptability of control structures with action complements, but they considerably disagree on the acceptability and the controller assignment in the case of nonprototypical complements, cf. sentences (3) and (4).

(v) Finally, speech act analysts have stressed that promises, requests, etc. require the propositional content condition that the speaker or the addressee perform a future action, cf. Searle (1969), Wierzbicka (1987).

We assume that the meaning and use of the verbs in Table 1 give rise to various semantic-pragmatic roles, which are assigned to the subject and object of the matrix clause and to $P R O$, the understood subject of the infinitive clause. The foremost semanticpragmatic role is the Agent, which, in the prototypical case, is supposed to perform the action denoted by the complement clause; i.e. with COMMISSIVES, the subject of the matrix clause, and with all other verbs, the direct or indirect object. This Agent will henceforth be called the 'prototypical controller'. The second semantic-pragmatic role introduced by the matrix verb will 
be called the Beneficiary, i.e. in the case of COMMISSIVES and CONSULTATIVES, this role is assumed by the matrix object, whereas in the case of DIRECTIVES and PERLOCUTIVES, it is the matrix subject which is associated with the role of Beneficiary. ${ }^{8}$ The situation is less clear with the IMPLICATIVES investigated: The subject of force/zwingen can easily be interpreted as Beneficiary, whereas the assignment of this role to the subject of induce/veranlassen seems to be highly context-dependent. Finally, we introduce the role Dependent: For example, the subject of bitten 'ask, request' is dependent upon the good will of the object of the matrix clause, whereas the (indirect) object of raten 'advise' or empfehlen 'recommend' is neutral with regard to this role, because the person denoted by the object is free to accept or reject the advice or recommendation given by the subject. The modal dürfen 'be allowed to', apart from assigning the role Beneficiary to its subject, also involves the dependence upon some authority, i.e. in a sentence like

(12) Die Sekretärin überredet den Chef PRO das Büro während der Weihnachtsferien schließen zu dürfen. 'The secretary persuaded the boss PRO to be allowed to close the office during the Christmas break'

$P R O$ is both a Beneficiary and a Dependent, and it is naturally linked to the subject of the matrix clause as its controller, since the secretary is both (potential) Beneficiary and Dependent. We will henceforth call the shifted controller the non-prototypical controller.

We regard the roles Agent, Beneficiary, and Dependent as labels which abbreviate pragmatic inference chains based on default assumptions about the world. These roles are independently motivated as necessary components of a semantic-pragmatic description of speech acts or speech act verbs, cf. e.g. Leech (1983), Bach \& Harnish (1979), Wierzbicka (1987). As an illustration, consider the verb bitten or its English near-equivalent ask. Wierzbicka

8 We assume that these roles are relevant for the control behavior of the verbs under investigation. This does not mean however that there are no other semantic-pragmatic roles which might be of importance in the analysis of other control verbs. 
(1987:50) defines the verb in the following way: "The asking person wants the addressee to do something that would be to his (the speaker's) benefit." The definition shows (i) that the speaker wants the hearer to do something. Given normal background assumptions, this proposition pragmatically implies, i.e. conversationally implicates, (ii) that the desired action is in the interest of or benefits the speaker. Since bitten and ask entail a (potential) action of the addressee, there is obligatorily a (prospective) Agent. Finally, bitten (but perhaps not ask) implicates that the person denoted by the matrix subject has the role Dependent. In addition to the roles mentioned above, there may of course be additional roles which are needed in the analysis of other control verbs. Consider for example

Der Pastor drohte den 1 Gläubigen
The pastor threatened the-DAT(PL) faithful-DAT(PL)
PRO Höllenqualen erleiden zu müssen.
PRO torments-of-hell suffer-INF to must-INF

In this sentence the verb drohen, in contrast to its English equivalent threaten, allows an indirect object (here: den Gläubigen 'theDAT(PL) faithful'), which functions as the controller of PRO. The latter is the subject of the modal müssen 'must' and may therefore be assigned the role Non-beneficiary ('Maleficiary'). The same role can be attributed to the indirect object of the matrix verb.

It should have become clear from the examples that semanticpragmatic roles in our sense should not be confused with 'deep cases' in some case-grammatical framework, cf. Rudanko (1989), or 'theta-roles' in generative grammar, as e.g. in Jackendoff (1972) or Růžička (1983a, b). A semantic-pragmatic role, in our model, is defined with regard to the situation or state of affairs denoted by the infinitival complement clause. E.g. in sentence (2), we regard the matrix object Joan as the Agent who is supposed to perform the action expressed in the complement clause. The subject Judy will be considered as the Beneficiary, since $J u d y$ will potentially benefit from this action. In a case-grammatical or a theta-role approach the matrix subject would be regarded as the Agent (or Source) and the matrix object as e.g. the 'Theme'. For linguists used to 'deep cases' in the classical sense, our approach, at first 
sight, may look bizarre. However, to our mind, it is cognitively plausible to assume that the matrix verb introduces a scenario with 'prospective roles' which are assigned to the arguments of the matrix clause. We intend to show in this paper that the concept of semantic-pragmatic role has the advantage of accounting for a number of control phenomena which, in the past, have been treated as exceptions. Table 2 lists the semantic-pragmatic roles which we think are relevant to the control behavior of the verbs under investigation.

Table 2: Distribution of prospective semantic-pragmatic roles.

\begin{tabular}{|l|l|l|}
\hline & Subject . & Object \\
\hline \multicolumn{2}{|c|}{ OBJECT CONTROL VERBS } \\
raten/- & 0 & $\mathrm{Ag}, \mathrm{Ben}$ \\
empfehlen/recommend & 0 & $\mathrm{Ag}, \mathrm{Ben}$ \\
bitten/request & $\mathrm{Ben}, \mathrm{Dep}$ & $\mathrm{Ag}$ \\
beschwören/implore & $\mathrm{Ben}, \mathrm{Dep}$ & $\mathrm{Ag}$ \\
überreden/persuade & $\mathrm{Ben}$ & $\mathrm{Ag}$ \\
überzeugen/convince & (Ben) & $\mathrm{Ag},(B e n)$ \\
veranlassen/induce & 0 & $\mathrm{Ag}$ \\
zwingen/force & $\mathrm{Ben}$ & $\mathrm{Ag}$, Dep \\
\multicolumn{2}{|c|}{ SUBJECT CONTROL VERBS } \\
versprechen/promise & $\mathrm{Ag}$ & $\mathrm{Ben}$ \\
zusagen/give one's word & $\mathrm{Ag}$ & $\mathrm{Ben}$ \\
\hline
\end{tabular}

$\mathrm{Ag}=$ prospective Agent of the action scenario introduced by the matrix verb

Ben $=$ prospective Beneficiary of the action scenario introduced by the matrix verb

Dep $=$ the role of the participant whose action is dependent on, or determined by, some other participant mentioned in the matrix clause

$0=$ 'unmarked' with respect to $\mathrm{Ag}$, Ben, or Dep.

Since these matrix verbs evoke an action schema, one of the matrix arguments is necessarily the (prospective) Agent, whereas all of the remaining semantic-pragmatic roles are more or less context-dependent. As examples illustrating this point, consider the following sentences: 
(14) a. Der Autohändler überredete den Kunden PRO das überteuerte Cabriolet zu kaufen.

'The car dealer talked the customer into buying the overpriced convertible'

(14) b. Der Professor überredete den Studenten PRO seine bahnbrechende Dissertation einzureichen.

'The professor persuaded the student to submit his pioneering dissertation'

In both sentences the matrix object receives the (prospective) Agent role. However, the assignment of the (prospective) Beneficiary role is a much more complex process: Whereas in (14)a. the subject of the matrix clause is interpretable as the Beneficiary, given our world knowledge about (certain) car dealers, this is not necessarily true of (14)b.; on the contrary, it is perhaps more reasonable to assume that the action expressed in the infinitive clause is in the interest of the student. Obviously, there are various parameters that influence role assignment, e.g. the meaning and use of the matrix verb, its nominal arguments and their meaning and use, the social relationship between the participants denoted by the arguments (e.g. symmetrical or hierarchical relationships), and situational knowledge. In what follows, we will attempt to reduce the influence of contextual factors by limiting ourselves to an investigation of sentences which exclusively contain proper names as nominal arguments.

As Table 2 shows, it is possible for a matrix argument to have more than one role assignment. Consider the following sentence:

(15) Pauline rät Uschi, der Schule den Rücken zu kehren. 'Pauline advises Uschi to quit her job in the school'

In this sentence the matrix object can have two roles: (i) the obligatory Agent role and (ii) the role of Beneficiary, which is derived via conversational implicature.

We now turn to the understood subject of the infinitival complement. Obviously, if the prototypical complement clause embedded under the above-mentioned matrix verbs contains an action predicate in the active voice, then the prototypical role of its implicit subject $(=P R O)$ must be Agent. In Köpcke \& Panther (1991), we have shown that, for the German control verbs listed in Table 1, the degree of agentivity is the most important factor 
determining the reference of $P R O$. Our basic hypothesis was that the more the degree of agentivity of $P R O$ decreases, the more the probability increases that the non-prototypical controller will be chosen, i.e. the object in the case of COMMISSIVES and the subject in all other cases.

The degree of agentivity of $P R O$ results from an interplay of the meaning of the predicate of the complement clause and extralinguistic knowledge (i.e. world knowledge). On the one hand, agentivity is determined by the intrinsic meaning of the predicate of the complement clause; on the other hand, it may be a context-specific property based on pragmatic inferences. We assume a continuum of agentivity ranging from 'high' to 'low' correlating with specific construction types of infinitival complements, which will be discussed below:

Figure 1: Scale of Agentivity

High Agentivity

Low Agentivity
A
B
C
D
$\mathbf{E}$

We shall illustrate the scalar points $\mathrm{A}-\mathrm{E}$ by means of the German verbs versprechen 'promise' (subject control) and bitten 'ask, request' (object control) before turning to the experimental results. As mentioned above, these verbs assign the role of the Agent to one of the matrix noun phrases. In the case of bitten the direct object is the Agent, whereas with versprechen it is the subject which assumes this role. In contrast, the role of the other matrix noun phrase can be defined as that of the Beneficiary. A promise conversationally implicates that the referent of the indirect object will benefit from the situation expressed in the complement clause, while with bitten, the subject will profit from the state of affairs denoted by the embedded clause. We hypothesize that, correlating with the decreasing agentivity of $P R O$, 'beneficience' will play an increasingly important role in the assignment of control relations. 
Complement type $A$ is the prototypical case. ${ }^{9}$

(16) Egon bittet Paul PRO den Computer anzuschaffen. 'Egon asks Paul PRO to purchase the computer.'

(17) Harry verspricht Jürgen PRO das Buch zu kaufen. 'Harry promises Jürgen PRO to buy the book.'

In these sentences, the action verbs anschaffen 'purchase' and kaufen 'buy' assign a high degree of agentivity to the empty slot $P R O$. Our hypothesis predicts that in (16) the object Paul will be the controller, while in (17) the subject Harry will assume this function.

Complement type $B$ is an adjectival phrase in predicative position, which denotes or at least implicates an action. This type is fairly close to the most prototypical type $\mathrm{A}$ :

(18) Paul bittet Egon PRO während der Mittagszeit ruhig zu sein.

'Paul asks Egon PRO to be quiet during lunchtime.'

(19) Jürgen verspricht Harry PRO das nächste Mal nachsichtig zu sein.

'Jürgen promises Harry PRO to be indulgent next time.'

We assume that in (18) and (19) the same control relations will obtain as in (16) and (17), respectively.

Complement type $C$ contains a non-actional verb such as bekommen, kriegen, erhalten 'receive' (in the active voice), which selects a 'recipient' as its subject:

(20) Paul bittet Egon PRO für den Kostümball eine Einladung zu bekommen.

'Paul asks Egon PRO to receive an invitation for the fancydress ball.'

(21) Harry verspricht Jürgen PRO die Schallplatte so schnell wie möglich zu kriegen.

9 Speech act analysts have usually emphasized the fact that e.g. promises, requests, etc. require the propositional content condition that the speaker/addressee perform a future action. Moreover, it is obvious that action complements in the active voice are much more frequent with these verbs than e.g. passive complements. 
'Harry promises Jürgen PRO to receive the record as soon as possible.'

Although in (20) and (21) bekommen and kriegen semantically do not express actions, they nevertheless have a subject which may play an active part in the process of receiving or getting the object in question, e.g. the record in (21). In this case, both verbs would be interpreted as actional, with the pragmatically implicated meaning 'get, provide'. Usually, however, at least in German, $P R O$ has a relatively low degree of agentivity in complement type C. Instead, in the context of (20) and (21), it is plausible to regard $P R O$ as the Beneficiary of the state of affairs denoted by the verbs kriegen and bekommen. In case $P R O$ is interpreted as Beneficiary, a control switch from subject to object control (versprechen) and from object to subject control (bitten) is likely to occur. The reason for this control switch can be seen in semantic-pragmatic features of the illocutionary verbs versprechen and bitten: The addressee of a promise, who is grammatically realized as the indirect object in (21), is regarded as the Beneficiary of the state of affairs expressed in the infinitival complement, and the indirect object is therefore the most plausible candidate for assuming the role of controller. On the other hand, with a verb like bitten, the person denoted by the subject $\mathrm{NP}$ in (20) is supposed to benefit from the situation denoted by the infinitive clause; $P R O$ is therefore likely to have the subject NP of the matrix clause as its antecedent. It should be stressed again here that the identification of the controller is determined on the basis of both linguistic and factual knowledge.

Complement type $D$ contains the modal auxiliary dürfen 'be allowed to'. Intuitively, the subject of dürfen has a still lower degree of agentivity than bekommen/kriegen/erhalten. Semantically there is virtually no agentivity at all, and pragmatically it is difficult to imagine a context in which the subject of dürfen plays an active role. This type is exemplified by sentences such as

(22) Paul bittet Egon PRO in der Mannschaft mitspielen zu dürfen.

'Paul asks Egon PRO to be allowed to join the team.'

(23) Jürgen verspricht Harry PRO ins Kino gehen zu dürfen. 
'Jürgen promises Harry PRO to be allowed to go to the movies.'

The low degree of agentivity of $P R O$ leads to a foregrounding of the pragmatic Beneficiary role. Under these circumstances, we predict a reversal of the prototypical control relations in sentences (22) and (23), i.e. in (22) Paul will be the controller, whereas in (23) Harry will be the antecedent of PRO.

Complement type $E$ contains a passive construction, which induces a maximally non-actional interpretation of the complement clause. The subject of a passive construction is semantically (almost) non-agentive. The passive can be viewed as the prototypical syntactic construction expressing virtually 'zero agentivity' of its subject. Pragmatically, it is even harder, though not completely impossible, to figure out a situation in which $P R O$ might receive an inferentially-derived agentive reading. This complement type is illustrated by (24) and (25):

(24) Paul bittet Egon PRO bei der Arbeit unterstützt zu werden. 'Paul asks Egon PRO to be helped with his work.'

(25) Jürgen verspricht Harry PRO befördert zu werden. 'Jürgen promises Harry PRO to be promoted.'

The low degree of agentivity approaching zero facilitates an interpretation of $P R O$ as Beneficiary. Thus, in (24) the most likely controller is the matrix subject Paul, whereas in (25) this role is assumed by the indirect matrix object Harry.

In general, we assume that the interpretation of control relations in German (at least for the verbs listed in Table 1) is guided by a Principle of Identity of Semantic-Pragmatic Roles. If an NP can be identified in the matrix clause which has the same or roughly the same role as $P R O$, then this specific NP is selected as the controller. ${ }^{10}$ Preferably, this NP should be an Agent. In other words, coreference between two Agents, i.e. a matrix NP and $P R O$, is the optimal interpretive configuration, whereas the possibility that there is role identity between two Beneficiaries is only explored in those cases where the identity of Agents fails. For

10 Note again that 'pragmatic roles' in our sense should not be confused with the notion of theta-role, cf. Rüžička $(1983 a, b)$. 
example in (16) above, the semantic and pragmatic description of the matrix verb bitten has to make reference to an addressee, who is supposed to comply with the request, i.e. who has the pragmatic role Agent with regard to the propositional content expressed by the infinitive clause. Therefore, the object NP will be identified as the controller just in case $P R O$ can be interpreted as the subject of an action verb. With a commissive verb like versprechen in (17), the subject of the matrix clause is the Agent of a future action expressed in the complement clause. Consequently, the subject will function as the controller if the complement clause denotes an action.

Role identity is also the motivating force behind control switch. In (22) the object NP (Agent) is highly implausible as a controller, since it is obvious that $P R O$ has to be interpreted as a Beneficiary. This fact forces the hearer to search for a matrix NP which exhibits the same role as $P R O$, viz. the subject NP of the matrix clause. Conversely, in (23) the most plausible controller is the object NP of the matrix clause, because its pragmatic role (Beneficiary) is identical to the role of $P R O$ in the complement clause. The verbs versprechen and bitten seem to be highly flexible with regard to control switch. Intuitively, with other verbs, e.g. the CONSULTATIVES raten and empfehlen, control switch from prototypical object control to the more peripheral subject control in the contexts C, D and E is less natural. E.g. for a sentence like

?Klaus empfahl Uwe, vor dem Ausschuß eine Rede halten zu dürfen.

??'Klaus recommended Uwe to be allowed to deliver a speech to the committee.'

in contrast to bitten, the subject of empfehlen is not available for the role of Beneficiary; on the contrary, it is the person referred to by the indirect object who assumes both the roles of Agent and Beneficiary with regard to the propositional content expressed by the infinitive clause (cf. Table 2). Moreover, the act of recommending has as one of its felicity conditions that the addressee (the grammatical object) is free to perform or to reject the recommended course of action. Thus, it seems to us that empfehlen (like raten) implies a relatively high degree of 'independence' of the referent of the matrix object. Therefore, this matrix verb is 
pragmatically incompatible with a complement sentence containing dürfen, a modal verb which semantically conveys dependence on a third party authorizing the action.

It seems then that, with German control verbs, the assignment of the controller role to one of the NPs in the matrix clause is guided by a number of semantic and pragmatic principles. At first sight, there is no reason to believe that speakers of English apply different interpretive strategies when assigning a controller to the English equivalents of sentences (16)-(25).

On the other hand, there seem to be good reasons to question the cross-linguistic validity of this hypothesis. Some linguists, $\mathrm{cf}$. Comrie (1984) and Farkas (1988), have claimed that in English a sentence like

(27) Otto persuaded Helga to be examined by the doctor.

preferably receives an interpretation with the object NP as the controller. Comrie (1984:456) rejects the literal German translation of (27) as unacceptable:

(28) Otto überredete Helga, vom Arzt untersucht zu werden.

We do not share Comrie's acceptability judgment. Since Otto can be interpreted as the Beneficiary of the situation expressed in the complement clause and since $P R O$ is also plausibly assigned the role of Beneficiary, we predict that the matrix subject will control $P R O$. This reading is in accordance with the Principle of Role Identity. However, it remains an interesting fact that (27) with object control is most naturally translated into German as

(29) Otto überredete Helga, sich vom Arzt untersuchen zu lassen.

where sich untersuchen $z u$ lassen 'to have herself examined' expresses a causative (agentive) relationship between $P R O$ and the predicate of the complement clause. Sentence (29) perfectly conforms to the Principle of Role Identity, since the subject of the causative lassen is easily identifiable as Agent, which can be linked to the Agent defined by the matrix verb überreden.

The results of our experiments show that there are indeed some language-specific differences with regard to control properties between English and German. But we will demonstrate that 
most of these differences can be subsumed under the Principle of Role Identity.

In conclusion, the aim of our empirical investigation was to test the following hypotheses for the verbs listed in Table 1:

1. The Principle of Role Identity: The semantic-pragmatic roles of the controller and $P R O$ are identical or nearly identical. This principle subsumes the following cases:

2. a. In the prototypical case both the controller and $P R O$ are assigned the semantic-pragmatic role Agent.

b. In the non-prototypical cases, decreasing agentivity of $P R O$ is a precondition for control switch, i.e. for the selection of a non-prototypical controller. In other words, decreasing agentivity increases the probability of a control switch.

c. The probability of control switch is reinforced if $P R O$ is interpreted as Beneficiary and if it can be linked to an argument in the matrix clause, which in turn is also identifiable as Beneficiary. This matrix argument is of course distinct from the prototypical controller.

\section{EXPERIMENTAL DESIGN}

In order to verify our hypothesis on control assignment in English and German, we conducted two experiments with 35 native speakers of German and 28 native speakers of American English. In both experiments, the subjects were freshmen at the University of Hannover and the State University of New York at Buffalo, who, at the time the experiment was performed, had had no specific linguistic training. The subjects were between the ages of 19 and 26. An almost equal number of males and females participated in the experiments, but, since we discovered no sex-specific characteristics in the subjects' behavior, we shall not distinguish between the two sexes in the sections 4 and 5 .

The experiments were constructed around the control verbs given in Table $1 .^{11}$ Each verb was presented in the five different

11 As a matter of fact, one of the English 'subject control verbs' was the complex predicate give one's word. In what follows, we shall ignore this fact and shall simply refer to this phrase as a 'control verb'. 
syntactic contexts $(\mathrm{A}-\mathrm{E})$ mentioned above in section 2, yielding a total of 50 German and 45 English test sentences. The verbs used in construction type $\mathrm{C}$ were kriegen, bekommen, erhalten in German and get and receive in English. The German modal auxiliary dürfen in construction type $\mathrm{D}$ was rendered as be allowed to in English. In all sentences, the subject and the object slots of the matrix clauses were filled by proper names, either both male or both female, to avoid the possible interference of social and cultural factors in the interpretation of the test items.

All subjects were tested simultaneously. Each informant received a booklet, which contained one test sentence per page. The sentences were presented in random order, i.e. each subject was confronted with a different sequence. The subjects were instructed to read each sentence carefully and to respond spontaneously. They were asked not to dwell too much on specific sentences, nor to flip back and forth through the pages of the booklet.

After reading a sentence the subjects were asked to determine the controller of the implicit subject of the complement clause. The subjects' responses were elicited through a paraphrase of the infinitival complement clause, e.g. for the sentence

(30) Harry convinced Allan to try on the suit.

the content of the complement clause was paraphrased as

(31) In this sentence the speaker mentions the possibility or the fact that Harry/Allan tried on the suit.

The subjects had to select either the grammatical subject or the grammatical object of the matrix clause as the controller. Furthermore, the subjects also had the possibility to reject the test sentence as uninterpretable, i.e. as making no sense semantically and/or pragmatically.

The experiment did not include questions about the formal (morphosyntactic) well-formedness of the test sentences. We suppose that the sentences presented to our subjects were "grammatically" correct, though some of them were no doubt stylistically awkward in the sense that they do not seem to be in current usage. For example, the control verb promise, for many speakers of English, does not allow an indirect matrix object when construed with an infinitive clause, cf. Mair (1990). We assume that, 
syntactically, the control verbs under investigation freely admit embedded infinitive clauses of the form [PRO to/zu VP]. This includes the five construction types A-E exemplified above. Our aim was to elicit interpretations from our subjects which made sense to them in semantic and pragmatic terms. Only after having strained their interpretive imagination unsuccessfully had the subjects the option to mark the test sentence as semantically or pragmatically deviant. We will try to show that the oddity of certain sentences can exclusively be attributed to semantic-pragmatic factors.

\section{EXPERIMENTAL RESULTS ${ }^{12}$}

\subsection{Commissives}

For the prototypical infinitival complements, i.e. construction types $A$ and $B$, in both English and German the majority of the subjects chose the subject NP of the matrix clause as the controller. However, there is a remarkable difference between the English and the German data: While $100 \%$ or nearly $100 \%$, of the German speakers chose the subject NP as the controller, Table 3 shows that in English these rates are considerably lower and the decisions in favor of object control are surprisingly high. We will discuss this matter in section 5.2.

Furthermore, Table 3 reveals that with construction types D and $\mathrm{E}$, in both languages for the four matrix verbs, subjects are inclined to switch from subject to object control. Construction type $\mathrm{C}$, however, in the English data, patterns more like the prototypical types $A$ and $B$ in retaining subject control to a large extent, whereas in German there is a strong tendency to favor the object of the matrix clause as the controller. We will attempt to explain this interesting contrast in section 5.1 and subsequent subsections.

12 The subjects in the experiment were asked to select either one of the matrix NPs as the controller of PRO or to mark the test sentence as unacceptable. Subjects who chose more than one of these three options were not taken into consideration for that particular test item. This explains the variation in the numbers of subjects in the tables of this section. 
Table 3: Results for COMMISSIVES in English and German in percentages

\begin{tabular}{|c|c|c|c|c|c|c|c|c|c|}
\hline & \multirow{3}{*}{ Constr. types } & \multicolumn{8}{|c|}{ promise/versprechen } \\
\hline & & \multicolumn{2}{|c|}{$\mathrm{N}$} & \multicolumn{2}{|c|}{ Subj } & \multicolumn{2}{|c|}{ Obj } & \multicolumn{2}{|c|}{ reject } \\
\hline & & Engl & Ger & Engl & Ger & Engl & Ger & Engl & Ger \\
\hline A) & action verb & 27 & 35 & $70 \%$ & $100 \%$ & $15 \%$ & - & $15 \%$ & - \\
\hline B) & adj. phrase & 28 & 35 & $71 \%$ & $100 \%$ & $18 \%$ & 一 & $11 \%$ & - \\
\hline C) & get-constr. & 28 & 34 & $68 \%$ & $43 \%$ & $25 \%$ & $49 \%$ & $7 \%$ & $6 \%$ \\
\hline D) & be allowed to & 27 & 35 & $30 \%$ & $23 \%$ & $52 \%$ & $74 \%$ & $19 \%$ & $3 \%$ \\
\hline E) & passive & 28 & 35 & $14 \%$ & $9 \%$ & $\mathbf{7 1 \%}$ & $86 \%$ & $14 \%$ & $6 \%$ \\
\hline & & & & $g$ & & 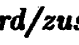 & & & \\
\hline A) & action & 28 & 35 & $82 \%$ & $97 \%$ & $18 \%$ & $3 \%$ & 一 & - \\
\hline B) & adj. phrase & 28 & 35 & $89 \%$ & $91 \%$ & $7 \%$ & $3 \%$ & $4 \%$ & $6 \%$ \\
\hline C) & get-constr. & 28 & 35 & $79 \%$ & $20 \%$ & $18 \%$ & $74 \%$ & $4 \%$ & $6 \%$ \\
\hline D) & be allowed to & 28 & 35 & $21 \%$ & $34 \%$ & $68 \%$ & $57 \%$ & $11 \%$ & $9 \%$ \\
\hline E) & passive & 27 & 35 & $11 \%$ & $9 \%$ & $74 \%$ & $91 \%$ & $15 \%$ & - \\
\hline
\end{tabular}

\subsection{Consultatives}

Consider next the results for the consultative matrix verb recommend and the German near-synonyms empfehlen and raten 'advise'. As Table 4 shows, recommend behaves quite differently from its closest German counterpart empfehlen. Table 4 also reveals that an overwhelming majority of the English speaking subjects, ranging from $85 \%$ to $93 \%$, preferred object control for all construction types. The German data show a $100 \%$, or nearly $100 \%$, preference for object control in the context of construction types A and B. Although for types D and E German speakers apparently hesitate to switch to subject control, nevertheless the figures for control switch to the subject NP are relatively high: e.g. empfehlen (construction type $\mathrm{D}=26 \%$, construction type $\mathrm{E}=46 \%$ ). Construction type $\mathbf{C}$ in German behaves quite differently from its English equivalent, since only slightly more than one half of the German subjects opted for object control. Another remarkable fact in the German data is the high rejection rate for the construction types $\mathrm{C}-\mathrm{E}$, ranging from $29 \%$ to $43 \%$. The German matrix verb raten roughly shows the same control pattern as empfehlen. 
Table 4: Results for CONSULTATIVES in English and German in percentages

\begin{tabular}{|c|c|c|c|c|c|c|c|c|c|}
\hline & \multirow{3}{*}{ Constr. types } & \multicolumn{8}{|c|}{ recommend/empfehlen } \\
\hline & & \multicolumn{2}{|c|}{$\mathrm{N}$} & \multicolumn{2}{|c|}{ Subj } & \multicolumn{2}{|c|}{$\mathrm{Obj}$} & \multicolumn{2}{|c|}{ reject } \\
\hline & & Engl & Ger & Engl & Ger & Engl & Ger & Engl & Ger \\
\hline A) & action verb & 28 & 35 & $4 \%$ & - & $93 \%$ & $94 \%$ & $4 \%$ & $6 \%$ \\
\hline B) & adj. phrase & 28 & 35 & $4 \%$ & - & $86 \%$ & $100 \%$ & $11 \%$ & - \\
\hline C) & get-constr. & 27 & 35 & $4 \%$ & - & $85 \%$ & $57 \%$ & $11 \%$ & $43 \%$ \\
\hline D) & be allowed to & 28 & 35 & $4 \%$ & $26 \%$ & $89 \%$ & $31 \%$ & $7 \%$ & $43 \%$ \\
\hline E) & passive & 28 & 35 & $11 \%$ & $46 \%$ & $86 \%$ & $26 \%$ & $4 \%$ & $29 \%$ \\
\hline & & & & & & en & & & \\
\hline A) & action verb & & 35 & & - & . & $100 \%$ & & - \\
\hline B) & adj. phrase & & 35 & & - & & $100 \%$ & & - \\
\hline C) & get-constr. & & 35 & & $11 \%$ & & $54 \%$ & & $34 \%$ \\
\hline & be allowed to & & 35 & & $17 \%$ & & $40 \%$ & & $43 \%$ \\
\hline E) & passive & & 35 & & $40 \%$ & & $23 \%$ & & $37 \%$ \\
\hline
\end{tabular}

\subsection{Directives}

Table 5 demonstrates that, for construction types A and B, in general, almost $100 \%$ of the subjects voted for object control. This holds for both languages.

With construction types $\mathrm{C}-\mathrm{E}$, however, there is a strong contrast between the two languages: The German informants overwhelmingly preferred subject control, whereas the English speakers were much more inclined to stick to the prototypical controller (object control), the only noticeable exception being the matrix verb $i m$ plore in construction type D. Nevertheless; it is important to note that, at least for some English speakers, control switch is possible with the two directive verbs tested.

\subsection{Perlocutives}

For the prototypical construction types $A$ and $B$ the figures for both languages are almost identical, cf. Table 6 .

For types $\mathrm{C}-\mathrm{E}$, there is a clear contrast between the verbs persuade and überreden, whereas the verbs convince and überzeugen 
Table 5: Results for DIRECTIVES in English and German in percentages

\begin{tabular}{|c|c|c|c|c|c|c|c|c|c|}
\hline & \multirow{3}{*}{ Constr. types } & \multicolumn{8}{|c|}{ request/bitten } \\
\hline & & \multicolumn{2}{|c|}{$\mathrm{N}$} & \multicolumn{2}{|c|}{ Subj } & \multicolumn{2}{|c|}{ Obj } & \multicolumn{2}{|c|}{ reject } \\
\hline & & Engl & Ger & Engl & Ger & Engl & Ger & Engl & Ger \\
\hline A) & action verb & 27 & 35 & - & - & $89 \%$ & $100 \%$ & $11 \%$ & 一 \\
\hline B) & adj. phrase & 28 & 35 & - & - & $100 \%$ & $100 \%$ & - & - \\
\hline C) & get-constr. & 28 & 35 & $21 \%$ & $89 \%$ & $61 \%$ & $9 \%$ & $18 \%$ & $3 \%$ \\
\hline D) & be allowed to & 28 & 35 & $7 \%$ & $91 \%$ & $75 \%$ & $6 \%$ & $18 \%$ & $\mathbf{3 \%}$ \\
\hline E) & passive & 27 & 35 & $25 \%$ & $97 \%$ & $59 \%$ & - & $15 \%$ & $3 \%$ \\
\hline & & \multicolumn{8}{|c|}{ implore/beschwören } \\
\hline A) & action verb & 28 & 35 & - & $3 \%$ & $96 \%$ & $97 \%$ & $4 \%$ & - \\
\hline B) & adj. phrase & 28 & 35 & - & $6 \%$ & $96 \%$ & $94 \%$ & $4 \%$ & - \\
\hline C) & get-constr. & 28 & 35 & $18 \%$ & $37 \%$ & $82 \%$ & $37 \%$ & 一 & $26 \%$ \\
\hline D) & be allowed to & 26 & 35 & $50 \%$ & $86 \%$ & $35 \%$ & $9 \%$ & $15 \%$ & $6 \%$ \\
\hline E) & passive & 27 & 35 & $29 \%$ & $86 \%$ & $41 \%$ & $6 \%$ & $30 \%$ & $9 \%$ \\
\hline
\end{tabular}

Table 6: Results for PERLOCUTIVES in English and German in percentages

\begin{tabular}{|c|c|c|c|c|c|c|c|c|c|}
\hline & \multirow{3}{*}{ Constr. types } & \multicolumn{8}{|c|}{ persuade/überreden } \\
\hline & & \multicolumn{2}{|c|}{$\mathbf{N}$} & \multicolumn{2}{|c|}{ Subj } & \multicolumn{2}{|c|}{ Obj } & \multicolumn{2}{|c|}{ reject } \\
\hline & & Engl & Ger & Engl & Ger & Engl & Ger & Engl & Ger \\
\hline A) & action verb & 28 & 35 & $4 \%$ & $3 \%$ & $93 \%$ & $97 \%$ & $4 \%$ & - \\
\hline B) & adj. phrase & 28 & 35 & $4 \%$ & - & $96 \%$ & $100 \%$ & - & - \\
\hline C) & get-constr. & 28 & 35 & $14 \%$ & $83 \%$ & $82 \%$ & $11 \%$ & $4 \%$ & $6 \%$ \\
\hline D) & be allowed to & 28 & 35 & $43 \%$ & $74 \%$ & $43 \%$ & $9 \%$ & $14 \%$ & $17 \%$ \\
\hline E) & passive & 28 & 35 & $32 \%$ & $69 \%$ & $57 \%$ & $11 \%$ & $11 \%$ & $20 \%$ \\
\hline & & & & & inc & bet & & & \\
\hline A) & action verb & 28 & 35 & - & - & $100 \%$ & $94 \%$ & - & $6 \%$ \\
\hline B) & adj. phrase & 28 & 35 & - & $3 \%$ & $96 \%$ & $94 \%$ & $4 \%$ & $3 \%$ \\
\hline C) & get-constr. & 27 & 35 & $37 \%$ & $34 \%$ & $54 \%$ & $52 \%$ & $7 \%$ & $14 \%$ \\
\hline D) & be allowed to & 27 & 35 & $56 \%$ & $66 \%$ & $29 \%$ & $31 \%$ & $15 \%$ & $3 \%$ \\
\hline E) & passive & 27 & 35 & $56 \%$ & $66 \%$ & $36 \%$ & $20 \%$ & $7 \%$ & $14 \%$ \\
\hline
\end{tabular}


pattern very much alike. Most of the German informants preferred a switch to subject control with the verb überreden (up to $83 \%$ ). The rate for non-prototypical subject control is lower, though still remarkable, for convince and überzeugen. Thus, the figures for control switch for the English PERLOCUTIVES are, in general, lower than for their German counterparts, but it should be noted that the verb convince is the only English object control verb which scored more than $50 \%$ for non-prototypical subject control in the two contexts $\mathrm{D}$ and $\mathrm{E}$.

\subsection{Implicatives}

Table 7: Results for IMPLICATIVES in English and German in percentages

\begin{tabular}{|c|c|c|c|c|c|c|c|c|}
\hline \multirow{3}{*}{ Constr. types } & \multicolumn{8}{|c|}{ induce/veranlassen } \\
\hline & \multicolumn{2}{|c|}{$\mathbf{N}$} & \multicolumn{2}{|c|}{ Subj } & \multicolumn{2}{|c|}{ Obj } & \multicolumn{2}{|c|}{ reject } \\
\hline & Engl & Ger & Engl & Ger & Engl & Ger & Engl & Ger \\
\hline A) action verb & 28 & 35 & 一 & - & $89 \%$ & $100 \%$ & $11 \%$ & - \\
\hline B) adj-phrase & 28 & 35 & 一 & - & $93 \%$ & $97 \%$ & $7 \%$ & $3 \%$ \\
\hline C) get-constr. & 28 & 35 & $18 \%$ & $29 \%$ & $64 \%$ & $51 \%$ & $18 \%$ & $20 \%$ \\
\hline D) be allowed to & 27 & 35 & $39 \%$ & $20 \%$ & $37 \%$ & $60 \%$ & $22 \%$ & $20 \%$ \\
\hline E) passive & 28 & 35 & $25 \%$ & $40 \%$ & $46 \%$ & $29 \%$ & $29 \%$ & $31 \%$ \\
\hline & & & & force & . & & & \\
\hline A) action verb & 28 & 34 & $4 \%$ & - & $96 \%$ & $100 \%$ & 一 & - \\
\hline B) adj. phrase & 28 & 35 & $4 \%$ & - & $93 \%$ & $100 \%$ & $4 \%$ & - \\
\hline C) get-constr. & 28 & 35 & - & $60 \%$ & $96 \%$ & $17 \%$ & $4 \%$ & $23 \%$ \\
\hline D) be allowed to & 27 & 35 & $29 \%$ & $66 \%$ & $41 \%$ & $20 \%$ & $30 \%$ & $14 \%$ \\
\hline E) passive & 28 & 35 & $4 \%$ & $43 \%$ & $89 \%$ & $34 \%$ & $7 \%$ & $23 \%$ \\
\hline
\end{tabular}

Table 7 reveals that, for construction types $A$ and $B$, informants in both languages were heavily inclined to select the object of the matrix clause as the controller. With regard to construction types C-E, the verb force and its German equivalent zwingen show a striking contrast. While a majority of speakers (usually more than one half) opted for a control switch in the case of zwingen, apart from one exception (D), about $90 \%$ of the 
English-speaking subjects retained object control with the matrix verb force. The judgments for the verb induce and its German counterpart veranlassen are, by and large, comparable. Although a switch to subject control is possible with both verbs for construction types C-E, the figures do not exceed $40 \%$ or are even considerably lower.

\section{DISCUSSION}

In the following discussion we will focus on two parameters, which seem to follow quite naturally from the results of the two experiments. We shall call the two parameters to which English and German are sensitive to varying degrees in the assignment of control relations

(i) the Principle of Role Identity (cf. section 2),

(ii) the Principle of Iconicity.

We do not claim that these two principles are the only ones that govern controller choice and control switch for the class of verbs investigated. Rather, we are aware of the possibility that there may be other, albeit minor principles, which guide control assignment and the acceptability of certain control structures. ${ }^{13}$

\subsection{The principle of role identity}

5.1.1 Agent and Beneficiary. As compared with German, the results of our experiments reveal that there is a relatively strong tendency in English to retain the prototypical control relation. The graphs in Figures 2 and 3 represent the average scores for control switch for subject control verbs (cf. Table 3 ) and object control verbs (cf. Tables 4-7), respectively.

The English speaking subjects are more hesitant than their German fellow students to select a non-prototypical controller in those cases where PRO has a relatively low degree of agentivity. Figures 2 and 3 reveal that, in both languages, decreasing agentivity correlates with an increasing tendency to shift the controller. However,

In Köpcke \& Panther (1991), besides the requirement of role identity, we discuss 'manipulative strength' and 'semantic-pragmatic incompatibility of matrix verb and complement clause' as two additional factors that might influence controller choice and acceptability. 
Figure 2: Subject control verbs in English and German Average scores for control switch for construction type A-E

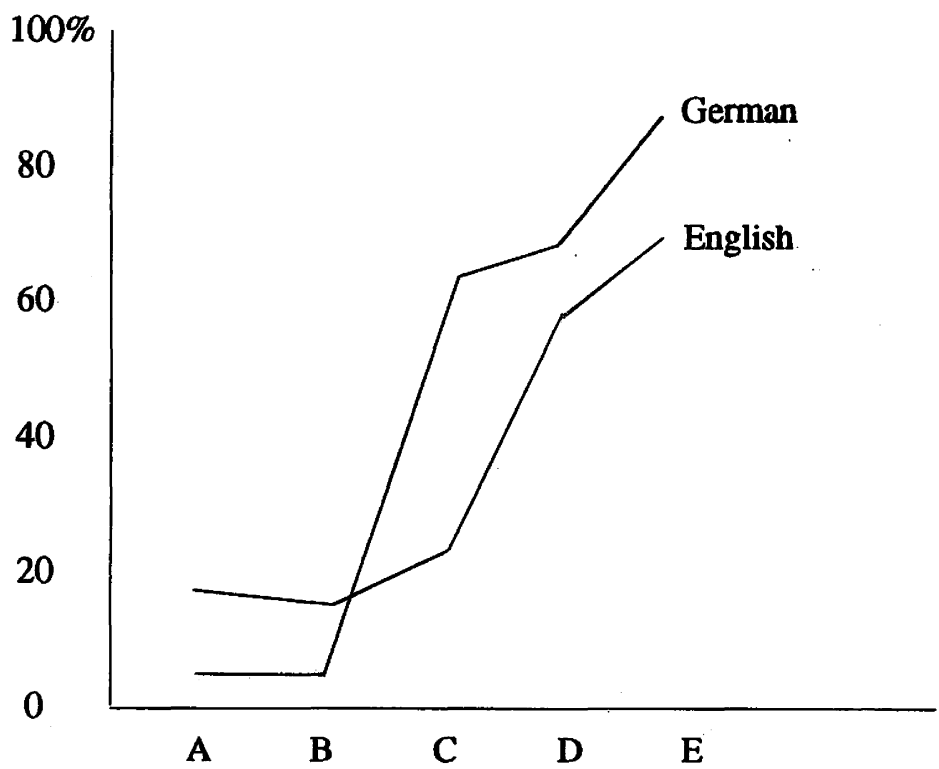

in English, this tendency is much more restricted. While Table 8 shows that for subject control verbs the results are similar, ${ }^{14} \mathrm{Ta}-$ ble 9 clearly suggests that a tendency towards control shift with English object control verbs is almost exclusively limited to the matrix verbs convince, implore, induce, and persuade in connection with construction type D ('be allowed to').

Thus, Figures 2 and 3 and Tables 8 and 9 provide evidence that the English speaking subjects prefer a pragmatically guided interpretation of $P R O$ as Agent. Indeed, this is the interpretation for which the matrix verb 'sets the stage'.

As an example illustrating how the Principle of Role Identity may function in English, consider the following experimental sentence:

(32) Mary requested Barbara to be helped with her work.

14 A chi-square test reveals that a comparison of the results for promise/give one's word vs. versprechen/zusagen in the context of construction types D and $E$ do not attain the .05 level of significance. 
Figure 3: Object control verbs in English and German: Average scores for control switch for construction type A-E

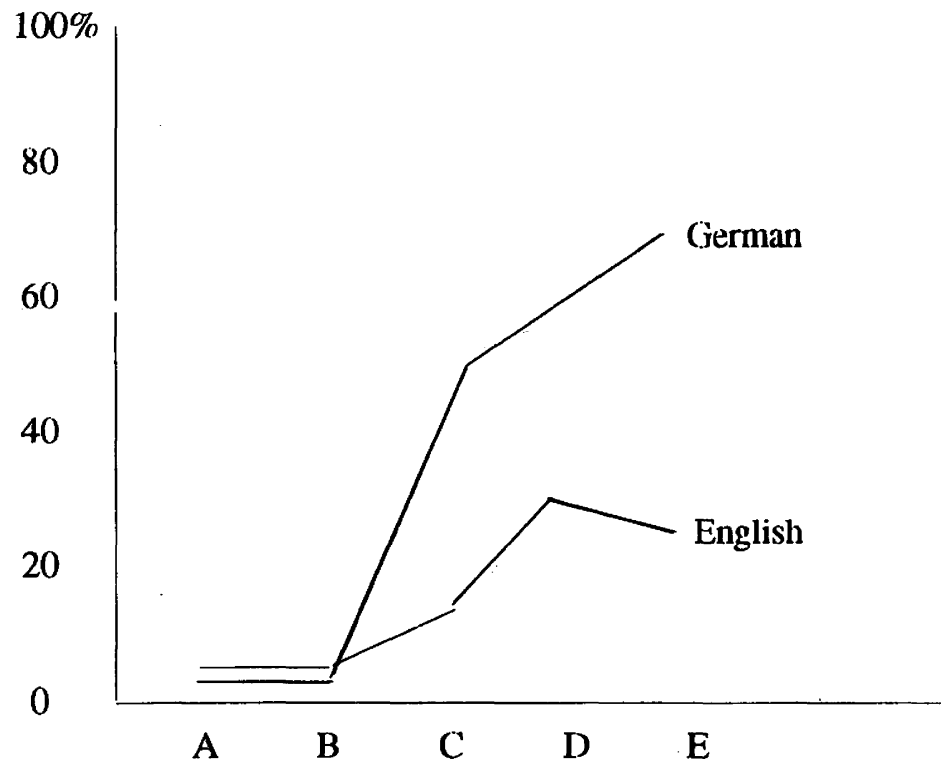

About $60 \%$ of the subjects prefer the prototypical object control, cf. Table 5, although prima facie PRO has a very low degree of agentivity. However, for sentence (32) to make sense pragmatically, the implicit subject of the infinitival clause must receive a reading which attributes an active role to the implicit subject (= $P R O$ ) of the complement clause. We assume a kind of metonymical process of reasoning here, which involves an inference from the result of an action (denoted by the passive clause) to the action proper, with the matrix object Barbara as the (voluntary) causer of the action.

Thus, there seems to be a tendency in English to interpret $P R O$ as Agent even if the complement sentence does not seem to justify such an interpretation. This interpretive strategy allows the native speaker of English to retain the prototypical controller and to satisfy the Principle of Role Identity at the same time.

The German speaking subjects obviously behave differently: In those cases where the complement clause does not match the scene set up by the matrix verb (construction types $\mathrm{C}-\mathrm{E}$ ) they 
Table 8: Preferred choice of informants for subject or object control with subject control verbs under conditions A-E in English and German*

\begin{tabular}{|c|c|c|c|c|c|}
\hline \multicolumn{6}{|c|}{$\begin{array}{l}\text { SUBJECT CONTROL VERBS } \\
\text { English }\end{array}$} \\
\hline & $\mathbf{A}$ & B & C & D & $\mathbf{E}$ \\
\hline promise & $S$ & $\mathbf{S}$ & $\mathbf{S}$ & 0 & 0 \\
\hline give one's word & $S$ & $S$ & $S$ & 0 & 0 \\
\hline \multicolumn{6}{|c|}{ German } \\
\hline & $\mathbf{A}$ & B & $\mathrm{C}$ & D & $\mathbf{E}$ \\
\hline versprechen & $S$ & $\mathbf{S}$ & 0 & 0 & 0 \\
\hline zusagen & $\mathbf{S}$ & $S$ & 0 & 0 & 0 \\
\hline
\end{tabular}

\footnotetext{
* $S=$ subject control

$\mathrm{O}=$ object control

$A=$ infinitival complement containing an action verb

$\mathbf{B}=$ infinitival complement containing an adjective implying an action

C = infinitival complement with 'get', 'receive'/"bekommen', 'kriegen', 'erhalten'

$\mathrm{D}=$ infinitival complement with 'be allowed'/'dürfen'

$\mathrm{E}=$ infinitival complement in the passive voice.
}

tend to select a controller which is semantically more compatible with the low-degree agentive meaning of PRO than the prototypical controller. They try to identify a matrix NP which is distinct from the prototypical controller and which can be assigned a similar or even identical semantic-pragmatic role, cf. Table 2. We illustrate this strategy by means of the German test sentence (24), repeated here as (33):

(33) Paul bittet Egon, bei der Arbeit unterstützt zu werden. 'Paul asks Egon to be helped with his work.'

In (33), in striking contrast to the English data, $97 \%$ of the experimental subjects opted for the subject NP as the controller. This reading seems to be motivated by an interpretive strategy which ascribes a non-agentive meaning to $P R O$, cf. hypothesis $2 \mathrm{~b}$ (cf. section 2). In pragmatic terms, it is plausible to assume that the subjects analyzed PRO as the Beneficiary of the situation described in the complement clause. This entails that the matrix object, which functions as the prospective Agent responsible for the state of affairs denoted by the complement clause, is not a 
Table 9: Preferred choice of the informants for subject or object control with object control verbs under conditions A-E in English and German*

\begin{tabular}{|c|c|c|c|c|c|}
\hline \multicolumn{6}{|c|}{ OBJECT CONTROL VERBS } \\
\hline \multicolumn{6}{|c|}{ English } \\
\hline & A & B & C & D & $\mathrm{E}$ \\
\hline convince & $\mathrm{O}$ & 0 & 0 & $\mathbf{S}$ & $S$ \\
\hline implore & 0 & $\mathbf{O}$ & O & $\mathbf{S}$ & 0 \\
\hline induce & 0 & 0 & O & $S$ & $\mathbf{O}$ \\
\hline persuade & 0 & 0 & $\mathbf{O}$ & $S=0$ & $\mathbf{0}$ \\
\hline request & 0 & $\mathbf{O}$ & O & $\mathbf{O}$ & $\mathbf{0}$ \\
\hline force & 0 & 0 & O & O & 0 \\
\hline recommend & 0 & 0 & 0 & $\mathbf{O}$ & $\mathbf{O}$ \\
\hline \multicolumn{6}{|c|}{ German } \\
\hline & A & B & c & D & E. \\
\hline bitten & 0 & 0 & $S$ & $\mathbf{S}$ & $\mathbf{S}$ \\
\hline überreden & 0 & 0 & $S$ & $S$ & $\mathbf{S}$ \\
\hline zwingen & 0 & 0 & $s$ & $\mathbf{S}$ & $S$ \\
\hline beschwören & 0 & 0 & $S=0$ & $S$ & $S$ \\
\hline üherzeugen & 0 & 0 & 0 & 0 & $S$ \\
\hline veranlassen & O & 0 & 0 & 0 & $S$ \\
\hline empfehlen & 0 & 0 & 0 & 0 & $S$ \\
\hline raten & 0 & 0 & 0 & O & $S$ \\
\hline
\end{tabular}

*cf. Table 8.

plausible controller of $P R O$, because its semantic-pragmatic status clashes with that of PRO (Agent vs. Beneficiary). Instead, it is the subject of bitten 'ask, request' which lends itself plausibly to an interpretation as Beneficiary. ${ }^{15}$

In what follows we shall demonstrate that the assignment of the role Beneficiary to the subject of object control verbs is an

15 We do not claim that the subject of bitten/request has the intrinsic property of being a Beneficiary. As noted above, we regard the roles which are relevant to control relations as (at least) partly inferentially derived. We assume that the native speaker makes use of different domains of knowledge in the interpretation of the respective roles that $P R O$ and the potential controllers in the matrix clause may have. 
Figure 4: Mean scores for control switch for the German object control verbs bitten/beschwören (Subject $=$ Beneficiary) vs. raten/empfehlen (Object $=$ Beneficiary).

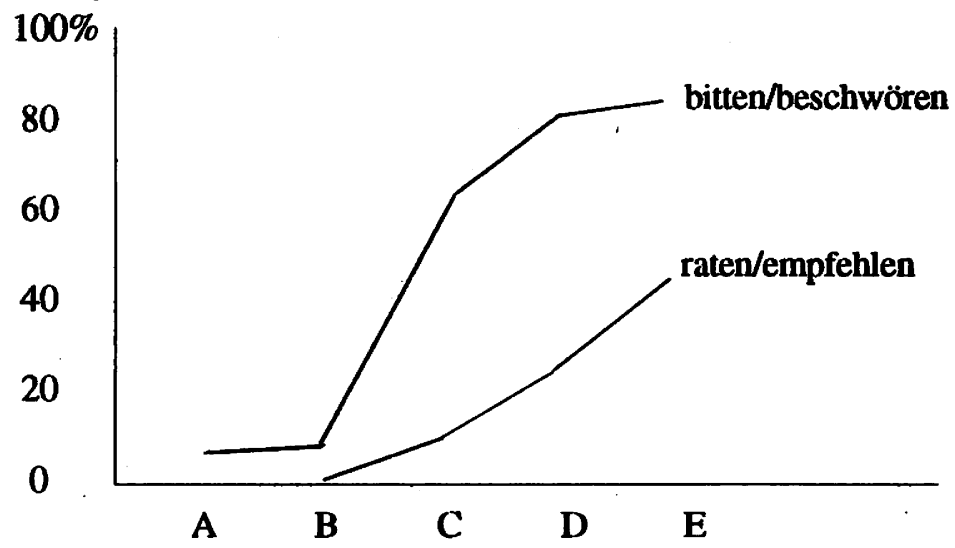

important factor, which may lead to control switch (i.e. subject control) in both languages, cf. Hypothesis 2c.

Figure 4 shows that decreasing agentivity of $P R O$ results in an increasing tendency to switch the controller. However, there is a significant difference between bitten/beschwören on the one hand and raten/empfehlen on the other. The contrast between directives and consultatives, with regard to control switch in the context of construction types D ('be allowed to') and E (passive), is highly significant. A chi-square test shows that for both construction types the level at which the null hypothesis can be rejected is smaller than .005 . We hypothesize that this difference is due to the Beneficiary role assigned to the subject of bitten/beschwören, which is absent in the matrix subject of raten/empfehlen. In principle, an analogous effect seems to be at work in English, cf. Figure 5 , although to a far lesser degree than in German.

In English the quantitative difference between request/implore and recommend is significant at the .01 level for construction type D, but only at the .1 level for construction type $\mathrm{E}$.

5.1.2 Dependent. Tables 3-7 show that in general the rejection rate for the test sentences is relatively low, except for the consultatives raten/empfehlen in contexts $\mathrm{C}-\mathrm{E}$. We assume that this 
Figure 5: Mean scores for control switch for the English object control verbs request/implore $($ Subject $=$ Beneficiary) vs. recommend (Object $=$ Beneficiary).

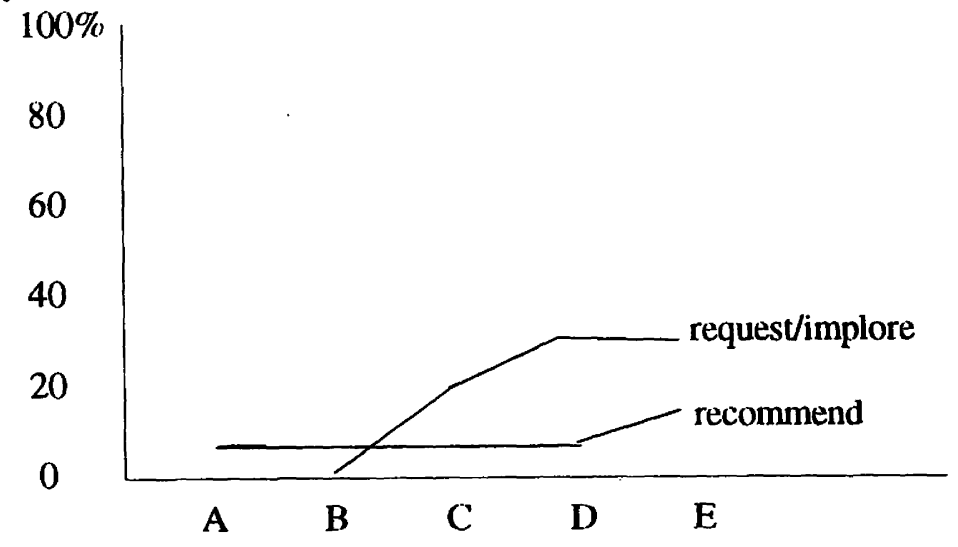

result is due to a pragmatic incompatibility between the role of $P R O$ and the roles of the matrix arguments. We will exemplify this hypothesis with regard to construction type $D$. In this context $P R O$ is assigned the role Dependent, i.e. the person denoted by $P R O$ is dependent on the authority or good will of some referent not mentioned in the complement clause. In the case of control verbs like bitten/beschwören it is fairly plausible to identify the direct object as the argument which (potentially) exercises his/her authority over the subject. Consequently, the subject of the matrix clause has the role Dependent and will thus be the most plausible antecedent of $P R O$. In contrast, the matrix verbs raten/empfehlen lack the role Dependent, cf. Table 2. Therefore, in the case of construction type $\mathrm{D}$, it is difficult to recover an adequate coreferential antecedent for $P R O$. This seems to be reflected in the relatively high rejection rate, cf. Table 4 . With respect to the rejection rate in context $D$, there is thus a telling contrast between bitten/beschwören and raten/empfehlen: the chi-square values for the two verb pairs reveal that this contrast is significant at the $<.005$ level. For context $\mathrm{E}$ the contrast between bitten/beschwören and raten/empfehlen, with respect to the rejection rate, is also highly significant $(<.005)$. The corresponding chi-square calculations for the English data do not reach the .1 
level of significance for construction type $D$, but are significant for construction type $\mathrm{E}(<.05)$.

As examples illustrating the above-mentioned contrast between directives and consultatives consider sentences (34) and (26), repeated here as (35):

(34) Elisabeth beschwört Monika, in der Arbeitsgruppe mit wirken zu dürfen.

'Elisabeth implores Monika to be allowed to join the team.'

(35) ?Klaus empfahl Uwe, vor dem Ausschuß eine Rede halten zu dürfen.

'Klaus recommended Uwe to be allowed to deliver a speech to the committee.'

In (34) Elisabeth is both Beneficiary and Dependent, Monika is the prospective Agent, and $P R O$ is Beneficary and Dependent. This is an optimal configuration for control switch: First, $P R O$ has a low degree of agentivity, which according to hypothesis (2b), cf. section 2 , is a prerequisite for control shift. Second, PRO has exactly the same role assignment as the matrix subject, and consequently, its most plausible antecedent is the subject NP Elisabeth.

In contrast, in (35) the subject NP Klaus is unmarked with respect to role assignment, cf. Table 2. The object NP Uwe is both Agent and Beneficiary and $P R O$ has the same role assignment as in (34). Again, low degree of agentivity encourages control switch. However, in this case, there is a counter-force, i.e. the Beneficiary role associated with the matrix object (the prototypical controller), which is at least partially compatible with the role assignment of $P R O$. These conflicting demands are reflected in the high rejection rates for raten/empfehlen in context D. Furthermore, the scores in Table 4 show that for context D more subjects opted for object control than for control switch. Finally, we suspect that the role Dependent might have been a factor resulting in the high rejection rate: While $P R O$, in context $\mathrm{D}$, is associated with the role Dependent, the matrix verbs raten and empfehlen suggest a more symmetrical relationship between the participants. As a result, many subjects seem to feel that the matrix clause and the subordinate clause are pragmatically incompatible, cf. Köpcke \& Panther (1991). 
A second argument supporting our claim that the role Dependent in the subject position of the matrix clause is an important factor motivating control switch can be derived from a comparison between the 'minimal pair' bitten/beschwören vs. überreden/überzeugen. These verbs exhibit the same role configuration, except for the role Dependent which is absent in the subject of überreden/überzeugen, cf. Table 2. Tables 5 and 6 show that, in German, the scores for subject control in context D are noticeably higher for the two directives than for the perlocutives. The contrast is significant at the .01 level. In other words, there is a perfect correspondence of roles (Ben, Dep) in the case of the directives investigated in context $\mathrm{D}$, whereas for the two perlocutives the requirement of role identity is only partially fulfilled $(P R O=$ Ben, Dep; matrix subject of perlocutives $=$ Ben $)$.

The corresponding English matrix verbs implore ${ }^{16}$ (directive) vs. persuade/convince (perlocutives) do not exhibit a significant contrast. Tables 5 and 6 show that for both verb types, apart from the idiosyncratic control properties of request (see fn. 16), control switch in context $\mathrm{D}$ is selected by about $50 \%$ of the experimental subjects. These results support again our claim that speakers of English tend to maintain the prototypical control relation, whereas for German speakers several factors, which have been isolated above, appear to facilitate or even force control shift.

\subsubsection{A schematized model of control. The following diagrams will illustrate in a more systematic way how the Principle of Role Iden- tity guides the interpretive strategies used by our experimental subjects. It should be stressed at this point that the flow charts represent tendencies in an idealized fashion. ${ }^{17}$ Furthermore, we}

16 The control verb request patterns quite differently from implore. The reasons that led the experimental subjects to maintain the prototypical object control to a large extent, even in contexts $D$ and $E$, are not entirely clear to us. We suspect that this behavior is due to the rather formal character of this verb, which might correlate with a relatively low degree of personal interest of the matrix subject (as compared to implore and German bitten/beschwören) in the propositional content of the complement clause.

Since the selection of a controller not only involves linguistic knowledge, but is rather, and more importantly, founded upon the language user's ability to make pragmatic inferences, there is nothing surprising about the fact that principles of controller choice can only be formulated as tendencies within the framework of the approach which has been argued for in this paper. 
only consider those cases where the Agent role and the Beneficiary role are attached to distinct matrix arguments. This particular role configuration is optimally suited for inducing control shift. ${ }^{18}$ In the following flow charts we will concentrate on what we consider to be the basic pattern of controller assignment, neglecting the role Dependent, which seems to be of importance only in context $\mathrm{D}$.

For the subject control verbs investigated we propose the interpretive schema in Figure 6. Here, as in Figures 7 and 8 below, the bold-lined rectangles represent prototypical controllers, i.e. Agents, whereas the lean-lined boxes symbolize non-prototypical controllers. Finally, the 'black' boxes indicate the different roles of $P R O$. The arrows labeled 'yes' are used to symbolize coreference between $P R O$ and its respective antecedent.

Level $I$ in Figure 6 schematizes the interpretive process underlying prototypical controller assignment for commissives. If $P R O$ has a high degree of agentivity (Level I), the Principle of Role Identity requires that $P R O$ be matched with the Agent introduced by the matrix verb, e.g. promise. This interpretive strategy is applied in both languages. Examples are sentences (1) and (17) above.

Level II applies whenever the interpretation of $P R O$ as Agent fails. At this point, speakers explore the possibility of identifying $P R O$ as a Beneficiary which matches the semantic-pragmatic role attributed to $\mathrm{NP}_{2}$. If this matching process succeeds, the matrix object will be chosen as the controller. Again, this seems to work for both languages.

Finally, if the non-prototypical control assignment on Level II fails, the sentence will be rejected as being uninterpretable. This decision is marked by a starred box in the flow chart. As a possible example consider the following sentence:

(36) Jürgen verspricht Harry, verprügelt zu werden.

'Jürgen promises Harry to be beaten up'

18 Of course we do not claim that this is the only relevant role configuration. Sentence (13) is an example that shows that the role configuration Maleficiary (matrix subject) and prospective Agent (matrix object) will also facilitate control switch, given the appropriate complement clause. The essential prerequisite is that the two relevant roles be assigned to distinct matrix arguments. 
Figure 6: Interpretive strategies underlying controller choice for subject control verbs in English and German (Commissives).

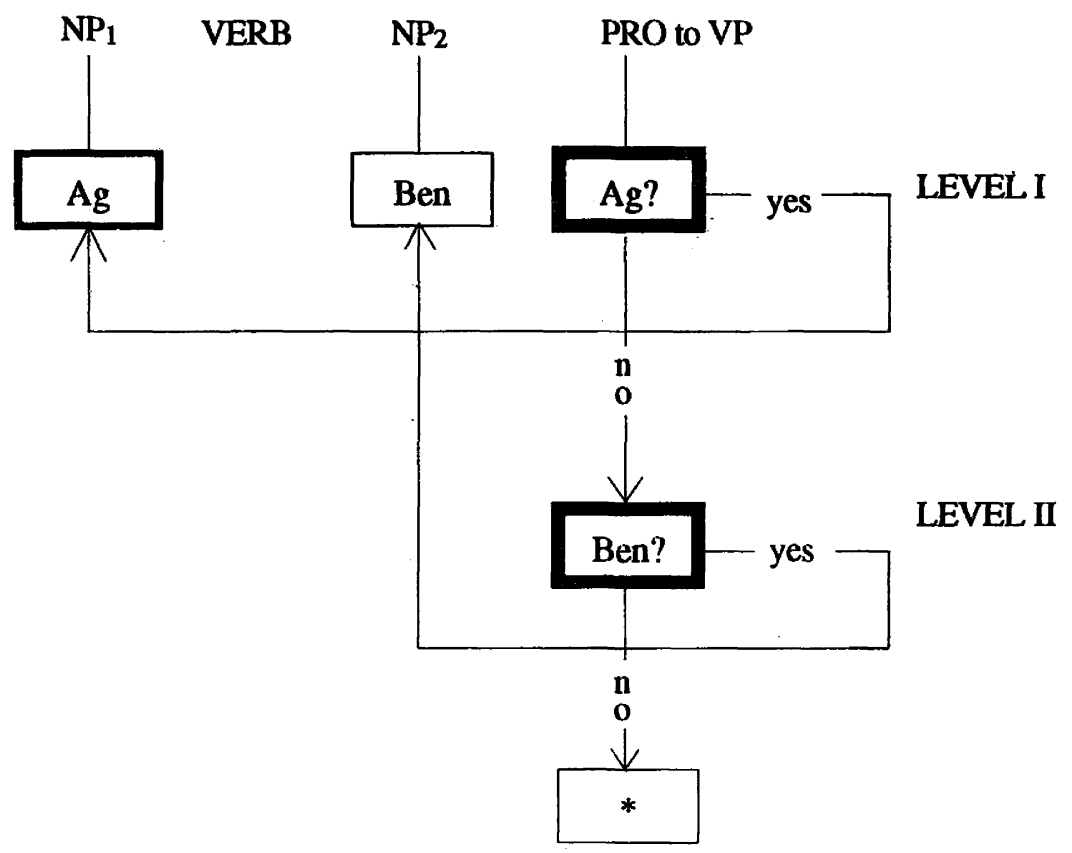

NP: $\quad$ matrix subject

$\mathrm{NP}_{2}$ : matrix object

VERB: matrix verb

to VP: infinitival complement

Ag: semantic-pragmatic role of Agent

Ben: semantic-pragmatic role of Beneficiary

Re-Ag: reinterpreted Agent, derived by means of pragmatic inferences, see Figure 8 *: $\quad$ uninterpretable utterance.

In this sentence $P R O$ has a low degree of agentivity (Level I), therefore the listener will try to interpret $P R O$ as Beneficiary (Level II). However, as the propositional content is normally not in the interest of the addressee, an interpretation of $P R O$ as Beneficiary will be highly implausible. ${ }^{19}$

One possibility to avoid the rejection of (36) is to assume a context in which versprechen 'promise' is reinterpreted as 'threaten'. 
Figure 7: Interpretive strategies underlying controller choice for object control verbs in German.

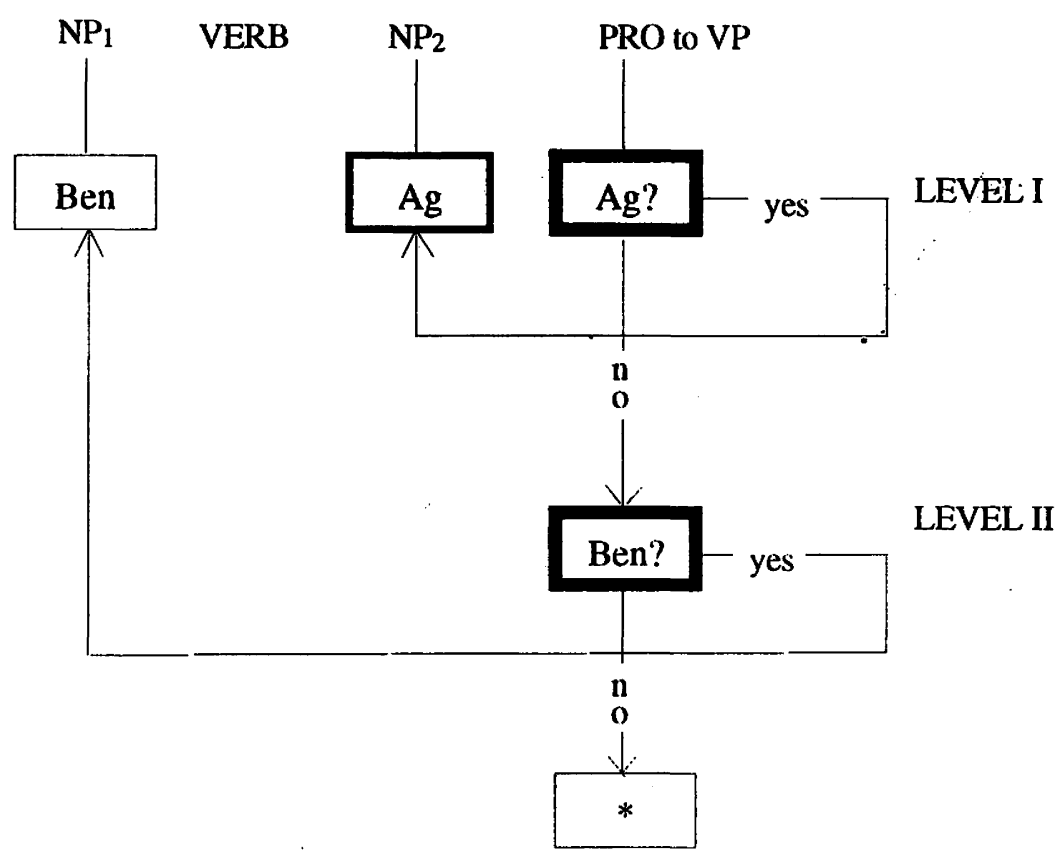

For abbreviations cf. Figure 6.

For the directives and perlocutives used in our experiments we propose the interpretive schemas given in Figures 7 (German) and 8 (English).

Level $I$ in Figures 7 and 8 refers to the prototypical case, where the complement clause denotes an action. Consequently, the option 'yes' is chosen for PRO and its antecedent is the matrix object. At this point the interpretive process is terminated. For Level I German and English behave exactly alike.

Level II in Figure 7 concerns those cases which involve gradually decreasing degrees of agentivity of $P R O$, cf. sentences (22) and (27). Here, the German subjects tend to explore the 'hypothesis' that $P R O$ is Beneficiary. If the 'yes'-option seems plausible, $P R O$ will coreferentially be linked to $\mathrm{NP}_{1}$ if the subject of the matrix verb can be pragmatically attributed the same role. Finally, 
Figure 8: Interpretive strategies underlying controller choice for object control verbs in English.

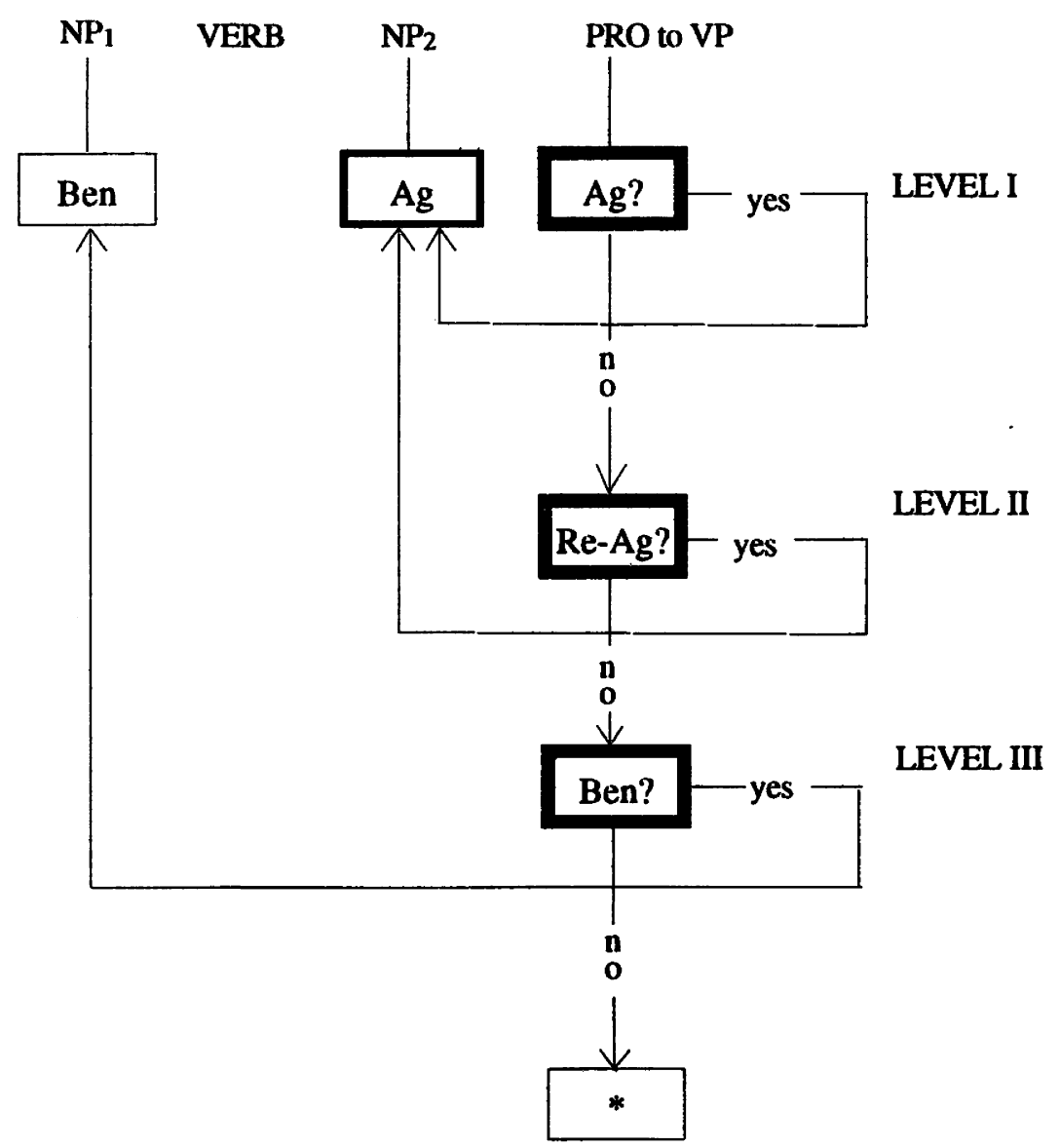

For abbreviations cf. Figure 6.

we assume that the sentence will be rejected as making pragmatically no sense if the Principle of Role Identity is not even applicable at Level II.

In contrast, in English there seems to be an intermediate interpretive strategy at work, before a control switch is envisaged, see Figure 8. This involves a reinterpretation of $P R O$, which, although semantically non-agentive, for pragmatic reasons can be 
assumed to play an active role in the situation, see Figure 8, Level II. As an example, consider the following experimental sentence:

(37) Mary requested Barbara to be helped with her work.

Almost $60 \%$ of the subjects, cf. Table 5, opted for object control, thus retaining the prototypical controller. This percentage is in striking contrast to the one for the near-synonymous German verb bitten. For this verb none of our German subjects decided on object control. Almost $100 \%$ shifted the controller in the case of bitten, whereas only $25 \%$ did so with request. Sentence (37), with object control, only makes sense pragmatically if the matrix object (Barbara) plays an active role in the situation expressed in the infinitive clause. A pragmatically meaningful, though somewhat clumsy, paraphrase of (37) would be (37a):

(37) a Mary asked Barbara $i$ that she ${ }_{i}$ should do something to the effect that somebody.would help her $i$ with her $i$ work.

The tendency observed for request is valid for the large majority of the English object control verbs we have investigated, cf. Table 9.

Perhaps one of the most interesting results which provides evidence for the hypothesis that speakers of English preferably interpret $P R O$ as Agent can be derived from the figures for complement type C, cf. Tables 3-7. The English recipient-oriented verbs get/receive (German bekommen/kriegen/erhalten) are read as actional predicates by an overwhelming majority of our Englishspeaking subjects, whereas the German subjects had a very strong tendency to switch the controller in the context of complement type C. It should be noted at this point that there are semanticpragmatic differences among the above-mentioned verbs: We assume that English get has both an actional and a recipientoriented reading, whereas receive semantically patterns more like German bekommen/kriegen/erhalten, all of which have a 'recipient' as their subject. With these verbs an actional interpretation can only be derived through pragmatic inferences. The ambiguity of get can be illustrated by sentences such as (38) and (39):

(38) He got (= received) a message from his friend. (non-actional) 
(39) He went to the bookstore and got (= bought) a book on linguistics. (actional)

Thus, although a direct comparison between the English and the German complement types $\mathrm{C}$ is not possible, since the abovementioned verbs are not exact synonyms, we believe that the fact that the subjects almost exclusively relied on the actional reading for complement type $\mathrm{C}$ in English provides strong support for our hypothesis that English favors an interpretation of $P R O$ as Agent.

Level III in Figure 8 represents the case where an interpretation of $P R O$ as an inferentially derived Agent is not plausible. Under these circumstances, our subjects will resort to control switch. This move will be facilitated if $P R O$ can be interpreted as a Beneficiary which can be coreferentially linked to an $\mathrm{NP}_{1}$ with the same semantic-pragmatic role. In comparison to the German data, the readiness of the English speakers to switch the controller is relatively weak: There is only one verb (convince) for which more than $50 \%$ of our experimental subjects applied Level III strategy, cf. Table 6, complement types D and E, i.e. they chose the subject (Beneficiary) as the controller. An example with a passive complement is given as (40):

(40) Allan convinced Harry to be included generously in his last will.

For the German object control verbs the figures for control switch are significantly higher. For the verbs bitten, beschwören, überreden, and überzeugen, all of which suggest a Beneficiary reading for $\mathrm{NP}_{1}$, speakers strongly tend to switch to subject control with complement types $\mathrm{D}$ and $\mathrm{E}$. The figures range from about two thirds up to nearly $100 \%$.

\subsection{The Principle of Iconicity}

A remarkable fact, however, which is in need of explanation, is the relatively high score which the English verbs promise and give one's word, in contrast to German versprechen and zusagen, obtained for object control in the context of construction types $A$ and B (e.g. $15 \%$ and $18 \%$ in the case of promise vs. $0 \%$ for versprechen, $\mathrm{cf}$. Table 3 ). Indeed, it has been observed by some 
scholars, e.g. Comrie (1984), that some native speakers only accept object control in connection with promise. For example, in a sentence like

(41) Bruce promised Brian to be patient with his children.

for a noticeable minority of speakers, the addressee of the promise, Brian, seems to be a plausible candidate who can act as an Agent in the situation described in the complement clause. This interpretation is in conflict with the Principle of Role Identity, since $P R O$ has a high degree of agentivity, whereas the matrix object Brian is conventionally associated with the Beneficiary role. The Principle of Role Identity predicts that $\mathrm{NP}_{1}$ (Bruce) should act as the controlling element, and it is indeed chosen by an overwhelming majority of our experimental subjects. Nevertheless, promise and give one's word are the only control verbs investigated to which, for the most prototypical construction types $\mathrm{A}$ and $\mathrm{B}$, a significant number of the subjects responded by deciding on the non-prototypical controller $\left(\mathrm{NP}_{2}\right) .{ }^{20}$

A possible explanation for this unexpected behavior could be that those speakers who opt for object control in sentences like (41) regard this sentence as a kind of a.c.i.-construction (raising construction), with an objectless matrix clause and Brian as the subject of the infinitive clause. This interpretation would be supported by the well-known fact that promise tends to be used without a matrix object, cf. Mair (1990).

This account has the disadvantage of being highly itemspecific, because it cannot be applied to the second COMMISSIVE give one's word, which shows parallel results, cf. Table 3. Thus, in general, English speakers seem to be more readily inclined to switch the controller with subject control verbs than with object control verbs. In other words, in this language, in

A chi-square test reveals that the scores for the non-prototypical readings of the two COMMISSIVES in the context of construction types $A$ and $B$ are highly significant in comparison to the corresponding figures with regard to CONSULTATIVES, DIRECTIVES, PERLOCUTIVES, and IMPLICATIVES. The null hypothesis, i.e. that these quantatative differences are accidental, can be rejected at the .001 level of significance. 
contrast to German, there is an overall tendency to prefer the object as the controller over the subject. ${ }^{21}$ With object control verbs, speakers of English are hesitant to switch from object control to subject control, even if the construction type of the complement (especially D and E) invites them to do so. The percentages for control switch, in most cases, remain well below the $50 \%$ mark, cf. Tables 4-7. On the other hand, for the subject control verbs promise and give one's word the percentages for object control in contexts $\mathrm{D}$ and $\mathrm{E}$ range from more than $50 \%$ up to almost $75 \%$, cf. Table 3 .

Given these facts, we propose for English a Principle of Iconicity, which does not seem to play any important role in German. ${ }^{22}$ In the case of object control verbs, this principle reinforces the choice of the object NP as the controller, whereas the same principle slightly reduces the tendency to select the subject as the controller with subject control verbs. Our Principle of Iconicity should not be confused with Rosenbaum's (1967, 1970) Principle of Minimal Distance, since the latter is assumed to be a purely syntactic constraint, whereas the Principle of Iconicity refers to a specific relationship between form and content/function. The Iconicity Principle in our sense says that the NP which is closest to the complement clause on the syntactic level is also most likely to be coreferential with the controlled element in the subordinate clause. Briefly then, formal closeness is reflected in referential identity.

21 The chi-square test shows that, in contexts $A$ and $B$, there is a significant contrast between zusagen/versprechen and promise/give one's word with respect to the selection of the object as the controller $(p<.05)$. It should however be mentioned that the expected cell values are smaller than 5 .

22

This difference between English and German is reflected in other grammatical domains, e.g. the position of a relative clause with regard to its head NP. In German in a sentence like Die Frau beobachtet den Mann, die/den der Junge umarmt 'The woman observes the man, who(m) the boy embraces' the head NP can be separated from the relative pronoun, since the latter agrees inflectionally with the former, whereas in the English translation only the closest matrix NP can function as the head, i.e. the man. 


\section{CONCLUSION}

Both experiments show that, to a certain extent, the subjects' responses deviated from the acceptability judgments found in the linguistic literature. This is especially true for construction types C-E. Furthermore, we discovered that language-specific interpretive strategies are exploited in the process of identification of the controller for PRO. Basically, German relies on the Principle of Role Identity. Generally, the matrix NP which assumes the Agent role is preferred as the controlling constituent. If, however, PRO has a low degree of agentivity and can be assigned the role Beneficiary, the Principle of Role Identity determines another controller, i.e. precisely that argument in the matrix clause which can be interpreted as the Beneficiary of the situation denoted by the complement clause. English satisfies the Principle of Role Identity differently by strongly adhering to a pragmatic reinterpretation of $P R O$ as Agent, even in contexts which do not support this reading at all, viz. construction types $\mathrm{D}$ and $\mathrm{E}$. This insistence on interpreting $P R O$ as Agent enables the speakers to retain the prototypical controller, i.e. the subject of subject control verbs and the object of object control verbs.

In addition, in English the assignment of control relations seems to be guided by the Principle of Iconicity, i.e., contrary to German, there is a fairly strong tendency to select the closest matrix NP as the controller of PRO. Usually, the two principles are not in conflict with each other: With respect to object control verbs the pragmatic reinterpretation of $P R O$ as Agent and the Principle of Iconicity reinforce each other. A conflict arises, as we have seen, in the case of the English subject control verbs in contexts A and B. Our experimental results seem to suggest the interpretation that semantic-pragmatic factors outweigh the Principle of Iconicity.

Finally, we would like to point out that the Principle of Role Identity is able to account for a number of recalcitrant data discussed in the literature on control phenomena. We shall restrict ourselves to two classes of cases. We will start out with sentences with a passivized matrix clause, assuming here that the grammatical judgements given in the literature on the subject are correct: 
(42) *John was promised PRO to leave.

(43) John was promised PRO to be allowed to leave.

(44) John was persuaded PRO to leave.

(45) *John was persuaded PRO to be allowed to leave.

In (42) there is a clash of semantic-pragmatic roles: PRO is clearly agentive, whereas the only available lexical controller (John) has the role of Beneficiary. Therefore, the Principle of Role Identity cannot be satisfied. The acceptability of (43) is predicted by the Principle of Role Identity. The grammatical matrix subject (John) can be given the same semantic-pragmatic role as $P R O$, viz. Beneficiary. In (44) the prospective Agent John perfectly matches the high degree of agentivity of $P R O$. Consequently, (44) poses no interpretive problems. Finally, sentence (45), like (42), exemplifies a case of role conflict. The Agent John cannot be linked to PRO since the latter is most naturally interpreted as a Beneficiary.

Our framework also takes account of sentences like

(46) The mother promised the children PRO to stay up till 11 p.m. (Larson 1991)

This sentence, apart from the subject control reading, can also have an interpretation where the children will enjoy the pleasure of staying up till 11 p.m. The children can be attributed the role of Beneficiary and since the implicit subject in the infinitive clause can also be assigned this role, its most plausible antecedent is $\mathrm{NP}_{2}$.

Addresses of the authors:

Klaus-Uwe Panther

Universität Hamburg

Englisches Seminar

Von-Melle-Park 6

D-W-2000 Hamburg 13
Klaus-Michael Köpcke

Universität Hannover

FB Erziehungswissenschaften I

Bismarckstr. 2

D-W-3000 Hannover 1 


\section{REFERENCES}

Bach, Emmon. 1979. "Control in Montague Grammar". 'Linguistic Inquiry 10, 515-531.

Bach, Kent \& Robert Harnish. 1979. Linguistic communication and speech acts. Cambridge, Mass. \& London: The M.I.T. Press.

Bartsch, Renate. 1978. "Infinitives and the control problem". Theoretical Linguistics 5, 217-250.

Bech, Gunnar. ${ }^{2} 1983$. Studien über das deutsche Verbum infinitum. Tübingen: Niemeyer. (Original edition 1955/1957)

Bresnan, Joan. 1982. "Control and complementation". Linguistic Inquiry 13, 343-434.

Chierchia, Gennaro. 1983. "Outline of a semantic theory of (obligatory) control". In M. Barlow et al. (Eds.). Proceedings of the West Coast Conference on Formal Linguistics (Vol. 2). Stanford: Stanford Linguistic Association, 19-31.

Chomsky, Noam. 1980. "On binding". Linguistic Inquiry 11, 1-46.

Comrie, Bernard. 1984. "Subject and object control". In Claudia Brugman et al. (Eds.). Proceedings of the Tenth Annual Meeting of the Berkeley Linguistics Society, February 17-20, 1984. Berkeley, CA: Berkeley Linguistics Society, 450-464.

Comrie, Bernard. 1985. "Reflections on subject and object control". Journal of Semantics 4, 47-65.

Farkas, Donka F. 1988. "On obligatory control". Linguistics and Philosophy 11, 27-58.

Foley, William A. and Robert D. Van Valin. 1984. Functional syntax and universal grammar. Cambridge: Cambridge University Press.

Givón, Talmy. 1980. "The binding hierarchy and the typology of complements". Studies in Language 4, 333-377.

Jackendoff, Ray. (1972). Semantic interpretation in generative grammar. Cambridge, Mass.: MIT Press.

Köpcke, Klaus-Michael \& Klaus-Uwe Panther. 1991. "Kontrolle und Kontrollwechsel im Deutschen". Zeitschrift für Phonetik, Sprachwissenschaft und Kommunikationsforschung 44, 143-166.

Koster, Jan. 1984. "On binding and control". Linguistic Inquiry 15, 417-459.

Ladusaw, William A. \& David R. Dowty. 1988. "Toward a nongrammatical account of thematic roles". In Wendy Wilkins (Ed.). Thematic relations (Syntax and Semantics 21). San Diego: Academic Press, 61-73.

Larson, Richard K. 1991. "Promise and the theory of control". Linguistic Inquiry 22, 103-139.

Leech, Geoffrey N. 1983. Principles of pragmatics. London \& New York: Longman.

Mair, Christian. 1990. Infinitival complement clauses in English. Cambridge: Cambridge University Press. 
Manzini, M. Rita. 1983. "On control and control theory". Linguistic Inquiry 14, 421-446.

Panther, Klaus-Uwe. In prep. Kontrollphänomene im Deutschen und Englischen aus semantisch-pragmatischer Perspektive.

Partee, Barbara. 1975. "Montague Grammar and Transformational Grammar". Linguistic Inquiry 6, 203-300.

Postal, Paul M. 1970. "On coreferential complement subject deletion". Linguistic Inquiry 1, 439-500.

Rohdenburg, Günter. 1991. Bemerkungen zu infiniten Konstruktionen im Englischen and Deutschen. Unpublished manuscript, University of Münster.

Rosenbaum, Peter S. 1967. The grammar of English predicate complement constructions. Cambridge, Mass.: The M.I.T. Press.

Rosenbaum, Peter S. 1970. "A principle governing deletion in English sentential complementation". In Roderick A. Jacobs and Peter S. Rosenbaum (Eds.). Readings in English transformational grammar. Mass.: Ginn and Company, 20-29.

Rudanko, Juhani. 1989. Complementation and case grammar: A syntactic and semantic study of selected patterns of complementation in presentday English. Albany, N.Y.: State University of New York Press.

Růžička, Rudolf. 1983a. "Remarks on control". Linguistic Inquiry 14, 309324.

Rưžička, Rudolf. 1983b. "Autonomie und Interaktion von Syntax und Semantik". In Rudolf Rưžička and Wolfgang Motsch (Eds.). Untersuchungen zur Semantik. Berlin: Akademie-Verlag, 15-59.

Sag, Ivan A. \& Carl Pollard. 1991. "An integrated theory of complement control". Language 67, 63-113.

Searle, John R. 1969. Speech acts: an essay in the philosophy of language. Cambridge: Cambridge University Press.

Thomason, Richmond H. 1976. "Some extensions of Montague grammar". In Barbara Partee (Ed.). Montague grammar. New York: Academic Press, 77-117.

Wegener, Heide. 1989. “'Kontrolle’ - semantisch gesehen: Zur Interpretation von Infinitivkomplementen im Deutschen". Deutsche Sprache 17, 206228.

Wierzbicka, Anna. 1987. English speech act verbs: a semantic dictionary. Sidney: Academic Press. 
